\title{
Schumpeter School
}

of Business and Economics

SCHUMPETER DISCUSSION PAPERS

\section{Maternal Employment and Childhood Overweight in}

\section{Germany}

Sophie-Charlotte Meyer 


\title{
Maternal Employment and Childhood Overweight in Germany
}

\author{
Sophie-Charlotte Meyer * \\ Schumpeter School of Business and Economics, University of Wuppertal \\ June 2015 - preliminary version!
}

\begin{abstract}
A widespread finding among studies from the US and the UK is that maternal employment is correlated with an increased risk of child overweight, even in a causal manner, whereas studies from European countries obtain less conclusive results. As evidence for Germany is still scarce, the purpose of this study is to identify the effect of maternal employment on childhood overweight in Germany using two sets of representative micro data. Moreover, we explore potential underlying mechanisms that might explain this relationship. In order to address the selection into maternal full-time employment, we use an instrumental variable strategy exploiting the number of younger siblings in the household as an instrument. While the OLS model suggests that maternal full-time employment is related to a 5 percentage point higher probability of the child to be overweight, IV estimates indicate a 25 percentage points higher overweight probability due to maternal fulltime employment. Exploring various possible pathways, we find that maternal employment is associated with unhealthy dietary and activity habits which might explain the positive effect of maternal employment on child overweight to some extent. Several sensitivity analyses confirm the robustness of our findings.
\end{abstract}

Keywords: maternal employment, childhood overweight, BMI, maternal labor supply JEL classification: I12, J22, J13

\footnotetext{
*Address for correspondence: Rainer-Gruenter-Str. 21, FN.01.03, 42119 Wuppertal, Germany, E-Mail: sophie.meyer@wiwi.uni-wuppertal.de. I would like to thank Hendrik Jürges for valuable comments which helped to improve earlier versions of this paper.
} 


\section{Introduction}

Childhood overweight has recently become a major public health concern, not at least because overweight children are at an increased risk to become overweight adults which is in turn associated with a number of health and social problems (see Cawley, 2011 Part 4 for an overview). Given the rising share of overweight children in nearly all developed countries, research has focused on various determinants of child overweight, apart from the major direct causes, excessive caloric consumption and lack of physical activity. As also female labor supply has been rising during the last decades, recent studies explore whether maternal employment is a determinant of child overweight. Theoretically, maternal employment implies a trade-off between time and money. On the one hand, employment reduces the mother's time to care for their children which might promote an unhealthy lifestyle with reduced physical activity or low-quality food. On the other hand, maternal employment increases family income which might enable the parents to invest in high-quality child care or healthy food. Consequently, the direction of the relationship between maternal employment and child overweight is a priori unclear and a positive as well as a negative relationship is conceivable. The empirical evidence is inconsistent regarding the direction of the relationship between maternal employment and child overweight and most of the existing studies focus on maternal employment in early childhood (e.g., Gwozdz et al., 2013) or the entire childhood (e.g., Nie and Sousa-Poza, 2014). A widespread finding among studies from the US and the UK is that maternal employment is correlated with an increased risk of child overweight, even in a causal manner (e.g., Anderson et al., 2003; Ruhm, 2008 for the USA; von Hinke Kessler Scholder, 2008 for the UK). This is in contrast to studies from other countries which obtain less conclusive results. Whereas a negative effect has been found for Denmark using an instrumental variable (IV) strategy (Greve, 2011), no relationship appears in cross-sectional data from China and selected European regions (Nie and Sousa-Poza, 2014; Gwozdz et al., 2013). Studies focusing on paternal labor supply consistently find no evidence that a father's employment status is related to child weight (e.g., Ziol-Guest et al., 2013; Miller, 2011; Greve, 2011).

As evidence for Germany is still scarce, the purpose of this study is to identify the effect of maternal employment on childhood overweight in Germany and explore potential underlying mechanisms that might explain this relationship. Exploring pathways is particularly important as it reveals potential factors which might contribute to the prevention of childhood overweight. We replicate previous findings for Germany and add to the existing literature in several ways. First, we focus on children in preadolescence (9 to 12 years old), which is found to be an important development stage. Children of this age are more likely to co-determine their allocation of time compared to younger children who depend more on their parent's decisions. Another reason for the focus on this specific age group is that in Germany, children typically change schools from primary to secondary school at about 10 years of age, which involves a range of changes for the children. Thus, maternal employment might impair the child's well-being especially during that age. However, evidence for the effects of maternal employment in preadolescence is still scarce and mostly confined to the US (e.g., Morrissey et al., 2011; Ruhm, 2008). 
Second, we aim to study the causal effect of maternal employment on preadolescent child weight in Germany. To our knowledge there is only one study that explores this relationship for Germany (Mahler, 2007). However, this study uses the German Socio-Economic Panel that solely includes self-reported body measures. Such measures are likely to be affected by measurement error/reporting heterogeneity and thus OLS estimates are likely to be biased. In order to explore the relationship between maternal employment and child weight, we mainly built our analyses on the German Health Interview and Examination Survey for Children and Adolescents (KiGGS). Although this survey is cross-sectional to date, it has substantial advantages compared to other data sources. ${ }^{1}$ In the KiGGS data, body height and weight are measured by trained medical staff and the data include information on birth weight and circumstances during pregnancy which allows us to control for initial child health. This way, we are able to mitigate the potential bias resulting from measurement error and reverse causality, which might occur if the mother stops working or reduces her hours worked because of the child's weight status or other adverse health conditions related to the child's overweight. In order to address the potential endogeneity of maternal employment, we use an instrumental variable approach using the number of younger children in the household to create external variation in maternal employment. ${ }^{2}$ A related instrument, the younger sibling's kindergarten eligibility age, has been previously used to instrument maternal employment (Morrill, 2011). In this study, we argue that the number of younger siblings in the household is likely to be a good instrument for maternal employment when controlling for a range of child and family characteristics, because it is strongly negatively related to maternal employment. With respect to the validity of the instrument chosen, we provide a theoretical discussion on the instrument and perform some sensitivity analyses. In order to further check the validity of our results and the instrument, we additionally base our analyses on a second data source, the German Microcensus. The main advantage of this supplementary data source is that it has a considerably larger sample size as it covers approximately 1 percent of the German households. These data also enable us to explore different definitions of maternal employment and to specify the instrument used more in detail. Finally, it is also revealing to compare the findings across different representative data sources from Germany.

Our final contribution lies in the exploration of possible pathways through which maternal employment is related to children's overweight. The KiGGS data are unique as they include detailed information on children's lifestyle behavior and conditions (such as the amount of sleep and family cohesion), which could potentially explain the relationship between maternal employment and childhood overweight. We assess whether circumstances that have been previously found to promote child overweight, for example unhealthy dietary habits, lack of physical activity or sleep, are associated with maternal employment as well. Thereby, we aim to yield further insights into

\footnotetext{
${ }^{1}$ Recently, the data has been already used to examine social determinants of child health (e.g., Reinhold and Jürges, 2012).

${ }^{2}$ Garcia et al. (2006) use the same instrument among other family characteristics when estimating the effect of maternal employment on child overweight using Spanish data. However, they simply conclude that the exogeneity of maternal employment cannot be rejected but the paper neither provides any results of the first stage or second stage, nor does it include a discussion on the instruments.
} 
the mechanisms underlying the relationship of interest. Moreover, making use of information on the mother's work schedules available in the German Microcensus data, we also investigate whether it matters when the mother works, although in a purely descriptive manner.

Our results suggest that maternal full-time employment is positively related to child overweight in Germany. OLS estimates indicate that maternal full-time employment is associated with a 5 percentage point higher probability for children aged 9-12 to be overweight. However, when the potential endogeneity of maternal employment is taken into account, estimates become even larger indicating that children of full-time employed mothers face a 25 percentage point higher probability to be overweight. Overall, several robustness analyses confirm the validity of our results and the instrument used as the estimates are quantitatively comparable. However, the estimates based on the KiGGS data become less precise which conveys the trade-off between accuracy and statistical power. With respect to the potential underlying pathways explored, we find that maternal employment is associated with a higher consumption of prepared food and soda drinks, a lower consumption of vegetables and fruits and increased sedentary behavior (watching TV and playing video games). Thus, our findings provide evidence that unhealthy dietary and activity habits might explain the positive effect of maternal employment on child overweight to some extent. Furthermore, descriptive analyses provide evidence that children of mothers who work non-standard hours, like working on Sundays or at nights, face a significant higher overweight probability. Taken as a whole, the findings suggests that it is the reduced maternal time spent with the child that might account for the relationship between maternal employment and child overweight.

The remainder of the paper is structured as follows: Section 2 briefly summarizes the previous literature and discusses some theoretical considerations concerning the underlying mechanisms of the relationship between maternal employment and child overweight. Section 3 introduces the two data sources, the KiGGS data and the German Microcensus. In Section 4 we discuss the empirical strategy used and the validity of the instrument while Section 5 shows the results of these analyses including several pathway and robustness analyses. Section 6 concludes.

\section{$2 \quad$ Related Literature and Theoretical Considerations}

We are aware of two studies that target this relationship in Germany. The recent study by Gwozdz et al. (2013) focuses on eight different European regions, including Germany and finds no significant association. However, as the data cover two small and relatively poor regions in Germany, the results obtained in this study are not representative and not generalizable to the wider population. Another study by Mahler (2007) uses German SOEP data and finds that maternal full-time employment during childhood increases a child's probability of being obese as young adult.

One problem that arises when estimating the effect of maternal employment on child outcomes is that maternal employment is likely to be endogenous for several reasons (Anderson et al., 2003; von Hinke Kessler Scholder, 2008; Greve, 2011; Morrill, 2011; Cawley and Liu, 2012). First, omitted 
variables might bias the results when different unobservable characteristics, like ability, motivate some mothers to work. ${ }^{3}$ For example, mothers with a higher ability might on the one hand be more likely to work but on the other hand they might also be more able to ensure a healthier lifestyle for the child which is in turn related to a lower probability of the child to be overweight. ${ }^{4}$ In this case, disregarding maternal ability would lead to an underestimation of the OLS estimate. Apart from that, working mothers could be thought of as generally less interested in their child's health as they prefer working over child care. Women who particularly enjoy spending time with their children might thus be less likely to work more hours (Anderson et al., 2003; Cawley and Liu, 2012). If those mothers were also more likely to indulge their children, omitting this characteristic would probably result in a downward bias. However, given that the opposite relation is also conceivable, the direction of the related bias is a priori unclear. As a second source of potential bias, reverse causality might occur if mothers are more likely to reduce working hours or stop working if their children suffer from adverse health conditions as unhealthy children might need more assistance. For example, Ruhm (2008) finds a significant effect of maternal employment in the year after the child's weight was measured which provides some evidence that this relationship might be evoked by reverse causality.

In several previous studies, researchers have already tried to isolate the causal effect of maternal employment on child overweight. Some studies apply child or family fixed effects in order to eliminate time-invariant unobserved child and family heterogeneity (Anderson et al., 2003; Ruhm, 2008; von Hinke Kessler Scholder, 2008; Ziol-Guest et al., 2013). For instance, Anderson et al. (2003) estimate different fixed effects models for children aged 3-11 from the NLSY and find that 10 additional working hours per week increase the child's probability to become overweight by 1.5 percentage points. Other studies use measures of the local labor market or local child care conditions as instrumental variables in order to isolate the causal effect of maternal employment on child overweight (Anderson et al., 2003; Garcia et al., 2006; Greve, 2011; Datar et al., 2014).

Maternal employment might promote or prevent child overweight at different ages to a different extent. Indeed, previous studies have found that the timing of maternal employment is important, showing that it especially increases the probability of child overweight in middle childhood. However, many previous studies focus on a long time span within the childhood and thus estimate an aggregate effect. This might result in misleading conclusions in case maternal employment might promote child overweight in one certain developmental period while it might prevent child overweight in another (von Hinke Kessler Scholder, 2008; Miller, 2011; Ziol-Guest, 2014). Besides the investigation of the mere relationship between maternal employment and child weight, previous work has increasingly focused on potential mechanisms why maternal employment is related to child overweight. Basically, maternal employment determines the mother's allocation of time

\footnotetext{
${ }^{3}$ Of course, the mother's choice to work may be driven by financial distress which depends on the household's financial conditions. We try to address this issue by controlling for the household income and the spouse's employment status.

${ }^{4}$ For example, Aughinbaugh and Gittleman (2004) and Ruhm (2004) show that not employed mothers have on average a lower ability and are less educated compared to employed mothers.
} 
spent working and time spent with the child. Therefore, when estimating potential pathways, it is helpful to focus on time-use information, either of the working mothers or of the child itself, as mechanisms are most likely related to these time constraints. ${ }^{5}$ Additionally, one could imagine that the time constraints maternal employment involves lead to less time spent on activities which promote child health, such as ensuring a healthy diet. Indeed, previous studies found that full-time employed mothers spend less time on food preparation, report fewer family meals and a lower level of fruit or vegetable intake (USA: Cawley and Liu, 2012; Bauer et al., 2012, Germany: Möser et al., 2012). For the US, Datar et al. (2014) found that the unhealthy food, which is more often consumed by children of working mothers, seems to mediate the effect of maternal employment on child overweight. In contrast, Gwozdz et al. (2013) find little evidence that maternal employment is related to caloric intake and physical activity in selected European regions. Contrary to the negative effect of maternal employment on dietary habits, maternal employment could also be thought to have a beneficial effect. For instance, a healthier but more expensive nutrition becomes affordable due to the increase in family income. However, previous studies find that the time constraints seem to dominate the income effect of maternal employment (e.g., Datar et al., 2014). Another imaginable pathway is that maternal employment involves a longer time without supervision which might promote an inactive lifestyle with a higher frequency of sedentary behavior, such as watching TV or playing video games. While it has been found that maternal employment is related to increased hours of watching TV in the US (Ziol-Guest et al., 2013; Datar et al., 2014; Fertig et al., 2009), there seems to be no relationship in Europe (Gwozdz et al., 2013). Altogether, evidence on underlying mechanisms how maternal employment is related to child overweight is still inconclusive given the strong distinctions between different countries. In this paper we aim to yield further insights into the pathways how maternal employment is related to child overweight in Germany. On the one hand, we focus on mechanisms that have already been investigated but led to mixed results, especially for countries outside the US: physical activity, dietary behavior and media consumption. On the other hand, we additionally look into other possible mechanisms on which previous research has paid little attention. Specifically, we assess whether the increased probability of child overweight among children of working mothers could be a consequence of a child's feeling of neglect. Maternal employment, and thus the reduced time spent with the child, might evoke a feeling of rejection of the child which might be compensated by eating. We explore this pathway using information on some indicators for family cohesion. Moreover, we also look into sleep as a special mechanism previously proposed by Ziol-Guest (2014), as too few hours of sleep have been found to be associated with a higher risk of being overweight (e.g., Chen et al., 2008), and otherwise might be related to maternal employment as well.

\footnotetext{
${ }^{5}$ Another pathway that is not directly related to the time constraints are food expenditures.
} 


\section{Data}

To estimate the relationship between maternal employment and child overweight our analyses are based on two sets of representative large scale surveys from Germany: the cross-sectional KiGGS data and four pooled cross-sections of the German Microcensus.

\subsection{The KiGGS Data}

Our main data source is the public use file of the KiGGS data. KiGGS is a nationally representative survey on the health of 17,641 German children aged 0-17 years old which was conducted during 2003-2006 (see Kurth et al., 2008 for details). Apart from collecting data in self-administered parental questionnaires and child questionnaires for children aged 11 years and older, the study also included medical interviews and examinations. We generally focus on information based on parental assessments for the sake of consistency except for the dependent variable. In rare cases, if only self-assessments are available (e.g. physical activity and amount of sleep), we rely on this information for children aged 11 years and older. Although the KiGGS study is planned as a panel study, only cross-sectional data derived from the baseline study are available for researchers to date. However, the main advantage of the KiGGS data is that body height and weight are measured by trained medical staff. Measured anthropometric measures are preferable to reported measures because it is less prone to reporting error e.g., due to social desirability. Moreover, the data include a full range of child and family characteristics and contain detailed information on the child's time use that allows us to explore possible mechanisms. For the purpose of this paper, the sample is restricted to children aged 9-12 years living with at least one biological parent. Furthermore, we exclude mothers that are currently enrolled in education as they might spend less time with their children due to schooling leading to an additional time constraint. Finally, we focus on individuals with non-missing data on variables used in the main specification. The final analysis sample includes 2,447 children (1,283 boys and 1,164 girls).

\subsection{The German Microcensus Data}

In order to obtain further evidence on the relationship between maternal employment and child overweight and to compare our findings across different representative data sources from Germany, we further use four cross-sections of the German Microcensus 1999, 2003, 2005, and 2009. ${ }^{6}$ Using the German Microcensus as a supplemental data source has several advantages over the KiGGS data. First, pooling the four cross-sections leads to a considerably larger sample size as the Microcensus is a representative official survey on the living situation of approximately 1 percent of the German households. Second, we are able to explore several definitions of maternal employment as this data

\footnotetext{
${ }^{6}$ This official data was provided by the Research Data Centers of the Federal Statistical Office and the Statistical Offices of the Länder in Düsseldorf, Germany, analyzed on-site (further information: http://www. forschungsdatenzentrum.de/en/).
} 
source includes more detailed information on the mother's employment situation. Third, as the Microcensus is conducted as a household survey, we are able to determine the age of the youngest child in the household, which allows us to further check the robustness of the instrument used in this study. The main drawback of the data is that the health-related information in the Microcensus is limited. Moreover, for children aged 15 and younger, information rests upon proxy reports of their parents. Compared to self-reported weight, parental reports on child weight have been found to be underestimated while reports on child height tend to be overestimated (Goodman et al., 2000). Within the Microcensus, child BMI is thus likely to be systematically affected by reporting bias, e.g., due to social desirability.

The analysis sample size is sizable and amounts to 45,210 boys and girls aged 9-12 years.

\subsection{Measuring Child Overweight}

Our main outcome of interest is the child's overweight status. We use the age- and sex-specific cut-off point recommended by the international obesity task force (IOT) that is comparable to the commonly used adult cut-off point of a BMI of 25 for being overweight (Cole et al., 2000). ${ }^{7}$ In another specification we use the BMI controlling for completed year-of-age dummies and the child's sex. Within the KiGGS data, we are able to additionally control for the exact age in days. In the samples used for the analyses, 21.50 percent of the children in the KiGGS data and 23.24 percent of the children in the Microcensus data are classified as being overweight. ${ }^{8}$

\subsection{Measuring Maternal Employment}

The predictor of interest is the mother's employment status. We differentiate between self-assessed full-time, part-time and not employed mothers (reference category) trying to take the intensity of maternal work at least to some extent into account. For the Microcensus, we additionally consider the average amount of maternal working hours per week divided by ten and four dummy variables for the maternal working hours in intervals of ten in some analyses. The KiGGS data do not include information on the number of working hours. Due to the cross-sectional design of both studies, it is not possible to consider the employment history or the cumulative maternal working hours since the birth of the child. However, Anderson et al. (2003) find that it is the hours per week which are directly related to the daily time constraints and not the weeks worked since birth that is related to the child's overweight status. Given the data available, we thus focus on the contemporaneous maternal employment status. Moreover, the contemporaneous maternal employment status is appropriate when we estimate some direct causes of child overweight like contemporaneous physical activity, sedentary behavior and some dietary habits. About 32 percent of the mothers in the KiGGS data and 35 percent of the mothers in the Microcensus data are not

\footnotetext{
${ }^{7}$ There is also a German cut-off point for child overweight (Kromeyer-Hauschild et al., 2001). The results are very similar when this definition of overweight is used in the analyses.

${ }^{8}$ Table A.2 in the Appendix provides some quantile regression estimates of maternal employment at different points in the BMI distribution.
} 
employed.

\subsection{Control Variables}

In order to obtain comparable results, we follow previous studies (e.g., von Hinke Kessler Scholder, 2008; Gwozdz et al., 2013) and include three different sets of control variables in our analyses distinguishing between child characteristics, maternal characteristics and other family characteristics. Child characteristics include the sex, age dummies and a residential variable for living in West/East-Germany. In analyses based on the KiGGS data, we are able to include additional controls, such as the exact age in days, three dummies for different levels of residence urbanization. Moreover, we are also able to control for characteristics of the child's initial health status by including the child's birth weight and an indicator of whether the child was breastfed. We also control for the person completing the parental questionnaires to take different patterns of reporting behavior between the mother and father into account (cf. Reinhold and Jürges, 2012). Within the Microcensus, the information is exclusively given by the child's mother, provided that the mother is living in the household. To capture possible time trends we additionally control for the survey year in the analyses based on the Microcensus.

Maternal characteristics include the mother's age group and four categories indicating her educational level. In the analyses based on the KiGGS data, we additionally consider indicator variables whether or not the mother gained weight, smoked or drunk during pregnancy. As the Microcensus lacks such information, we are only able to control for the mother's current smoking status in order to approximate her smoking behavior during pregnancy.

As family characteristics we consider dummies for the number of individuals in the household as well as four dummies for the maternal educational level (low, intermediate and high) including a category for missing information. To control for the child's ethnic background we include dummy variables whether the father and the mother have the German citizenship or not. The mother's employment status is likely to be influenced by the father's income and time investments which might in turn also be related to the child's weight. The data lack information on the father's income. ${ }^{9}$ In order to mitigate any potential bias, we include dummies for the household income as well as the father's employment status.

We also include the mother's and father's BMI with additional variables that indicate missing information. In some previous studies parental BMI is explicitly excluded from the analyses when estimating the causal effect of maternal employment on child overweight as it is likely to be endogenous (e.g., von Hinke Kessler Scholder, 2008). Maternal employment might not only affect the child's, but also the parent's weight as they are likely to share the same lifestyle and dietary habits within the family. However, we decided to include parental BMI with an additional category for missing values in our analyses for two reasons. First, parental BMI can also be interpreted as a proxy for genetic factors, which might bias the results as we are unable to control for that.

\footnotetext{
${ }^{9}$ For the Microcensus data, we are able to determine the father's income. The results are very similiar when the father's instead of the household income is used.
} 
Second, controlling for parental weight status is important with regard to our IV-approach in order to obtain consistent estimates as it might be related to both, our instrument and the outcome.

Table A.1 in the Appendix summarizes the main variables for both samples and reports the mean differences between overweight and not overweight children.

\subsection{Mechanisms}

In the selection of potential mechanisms that might explain the relationship between maternal employment and child overweight, we mainly follow Datar et al. (2014) and distinguish between different measures for dietary behavior (consumption of vegetables ${ }^{10} /$ fruits/soda drinks/sweets per day and consumption of junk food/prepared food per week), frequency of physical activity per week and hours of sedentary behavior (watching TV/playing video games per day ${ }^{11}$ ). The cut-off points are generally derived from the recommended amount of dietary consumption or physical activity also used by Datar et al. (2014). ${ }^{12}$ In addition, we take up the concern raised by Ziol-Guest (2014) that sleep should be considered when exploring mechanisms how maternal employment might affect child overweight. Our data contain information on the child's average amount of sleep per day as well as an indicator whether or not the child suffers from any sleep problems. Finally, we explore the contribution of variables indicating family cohesion, i.e. whether stringent regulations exist within the family or whether family activities are undertaken often.

These aforementiond child-related potential mechanisms are available in the KiGGS data only. However, the Microcensus includes information on maternal engagement in so-called non-standard work, i.e. working on Saturdays, working on Sundays or holidays, working in the evening (6pm-11 $\mathrm{pm}$ ) or at night (11pm-6am), and working at home. Focusing on the different maternal work schedules, we aim to assess whether it matters when the mother works. Previously, Morrissey et al. (2011) find only weak evidence that one summarizing measure of non-standard work is associated with child overweight in the USA, whereas Dunifon et al. (2013) provide some evidence that maternal night work is related to a higher probability of the child to suffer from behavioral problems. ${ }^{13}$

\section{Empirical Approach}

In order to empirically assess whether maternal employment is related to child overweight and child BMI in Germany, we apply a basic ordinary least squares model (OLS) in a first step. We estimate a linear probability model when overweight is the outcome of interest. As previously discussed, relying exclusively on an OLS approach is problematic as the mother's choice to work might be

\footnotetext{
${ }^{10}$ We use a combined measure of eating raw and cooked vegetables.

${ }^{11} \mathrm{We}$ use a combined measure of weekdays and weekend days.

${ }^{12}$ For some mechanisms (e.g., watching TV or playing video games) the cut-off points deviate from Datar et al. (2014) as these variables are collected in fixed categories that do not match with the definitions used by Datar et al.. However, robustness analyses using different thresholds point to the same direction.

${ }^{13}$ See Morrissey et al. (2011) for a detailed discussion on possible links why maternal non-standard work schedules might be associated with child overweight.
} 
driven by unobserved factors that are also related to the child's probability to be overweight. Several econometric approaches try to address the problem and previous studies implemented such models in order to isolate the causal effect of maternal employment on child outcomes. Household or child fixed effects (e.g., applied by Anderson et al., 2003; von Hinke Kessler Scholder, 2008) capture unobserved heterogeneity that is constant over time. However, this approach still does not solve the problem if the relationship is driven by reverse causality or if changes in maternal employment are not exogenous to the outcome, for instance, if mothers reduce their working hours to supervise their overweight children. Another commonly used approach is to find an instrumental variable that is correlated with maternal employment but uncorrelated with the error term. The difficulty is to find strong instruments that additionally fulfill the validity assumption to be uncorrelated with the error term. In previous studies maternal employment is most often instrumented by local labor market conditions (Anderson et al., 2003; Greve, 2011; Bishop, 2011; Datar et al., 2014). However, though this instrument seems exogenous at first sight, Cawley and Liu (2012) raise concern about the validity of such instruments. For example, previous studies have shown that macroeconomic factors, especially the local unemployment rate, affect health (e.g., Ruhm, 2008) and thus also the outcome of interest. In this study, we also try to address the possible endogeneity of maternal employment by a two stage least squares approach (2SLS) and instrument maternal full-time employment by the number of younger children in the household. ${ }^{14}$

\subsection{The instrument: Number of Younger Siblings in the Household}

Taking the number of younger children in the household as instrument rests upon the idea that the mother's incentive to work (full-time) is considerably lower if there is at least one younger child in the household. Regarding the mother's allocation of time, the opportunity costs to stay at home and care for the child of interest (older sibling) is substantially lower when there is another, younger child she has to care for already. Figure 1(a) and 1(b) show the relationship between the number of younger siblings in the household and maternal employment status within the two data sets. In general, it points to the assumed negative relationship: The share of part-time and fulltime employed mothers decreases with the number of younger siblings. While the highest share of full-time employed mothers (KiGGS: about 23 percent, Microcensus: about 21 percent) is among those without younger children, the lowest can be found among mothers with at least three younger siblings in the household (less than 5 percent). The descriptive relationship thus suggests that the number of younger siblings is highly relevant for maternal (full-time) employment which will be tested in the first stage regression (instrument relevance).

Another requirement in order to obtain valid IV estimates is that the instrument must be uncorrelated with the error term (instrument exogeneity). That means that conditional on the variables included in the model, the only path through which the number of younger siblings in the household is related to the child's overweight status/BMI, is maternal employment. Theoretically, one might expect that each additional (younger) child involves further time constraints which

\footnotetext{
${ }^{14}$ See Angrist (2001) and Morrill (2011), for a discussion on 2SLS models with a binary dependent variable.
} 
Figure 1: Maternal employment by the number of younger siblings in the household



(a) Source: KiGGS 2003-2006



(b) Source: Microcensus 1999, 2003, 2005, 2009

impair the maternal care for the older child, for example, to cook healthy meals. In this case, the instrument used would be invalid, as it would correlate with the child's weight. However, cooking succumbs substantial economies of scale which implicates that cooking for one child is more or less equal to the effort required to cook for two or three children. ${ }^{15}$ More generally, one might suspect that the number of younger siblings as a family characteristic is related to characteristics that determine the child's overweight status, e.g., through father's time investments, the financial condition of the family, genes or shared dietary habits. To address this, we include the father's employment status, family income and the parental BMI to proxy these factors. That way, we aim to capture these channels through which the instrument could be related to the child's weight status and thus mitigate any potential bias.

Another concern which is even more difficult to address arises from the fact that the number of younger siblings in the household might itself be correlated with unobservable characteristics, like maternal ambition or effort (c.f. Morrill, 2011). Although this seems to be counterintuitive, one could argue that more ambitious mothers are more likely to work full-time but are in turn also more likely to have more (younger) children. In view of the fact that the number of children generally decreases with female educational level (Destatis, 2012) and that ambition is likely to be positively correlated with education (e.g., Aughinbaugh and Gittleman, 2004; Ruhm, 2004), this bias is negligible. If ambitious mothers were nevertheless more likely to have younger children, the IV estimates might be downward-biased. The downward bias results from the positive correlation between maternal effort and the probability to work on the one hand, but the negative correlation between maternal effort and the child's probability to be overweight on the other. As maternal full-time employment appears to be strongly positively correlated to the child's BMI and overweight

\footnotetext{
${ }^{15}$ In a robustness check, we included the child's dietary and activity habits in the analyses to rule out the possibility that having younger siblings affects the cooking behavior of the mother, which would be a possible channel through which the number of younger siblings affect the other sibling's weight. However, the results are very similar.
} 
probability in this study, this bias would lead to an underestimation of the true effect.

As another objection, one could argue that the number of younger siblings correlates with the birth order of the children. Although we are not aware of any study assessing the causal link between being first-born (or birth order in general) and child overweight, few epidemiological studies found that firstborn children are more likely to become overweight (e.g., Li et al., 2007) which would impair the validity of our IV estimates. However, it is arguably difficult to identify a causal link in this context, as the appropriate reference group for first-born children consists of later-born children without older siblings. Moreover, this correlation might occur exactly because of maternal employment, a social mechanism which is neglected by the epidemiological literature. Nevertheless, in a robustness check in Section 5.4, we exclude first-born children and children without older siblings in the household, in order to eliminate the effect arising from being the first-born child. That way we are at least able to check if the IV estimates are biased due to a systematic correlation between being first-born and child overweight.

We believe that while controlling for a range of family and child characteristics to mitigate any potential bias, the number of younger siblings is likely to be a good instrument as it is strongly related to maternal full-time employment. In the main specification, we treat the instrument linearly as it turns out to have the strongest predictive power.

\subsection{Mechanisms}

We explore several possible mechanisms why maternal employment is related to the child's overweight status. However, given the problems that arise in identifying mediators in a causal sense (see Bullock et al., 2010) we do not perform a full mediation analyses. Instead, we only examine if maternal employment is causally related to the possible mediation variable and thus only estimate the first path in the Baron and Kenny (1986) mediation framework. Any variable that is significantly related to maternal employment indicates a possible channel through which maternal employment is related to the child's weight. However, as we are not able to test the other path, the results cannot be interpreted as a causal evidence for a mechanism in the relationship of interest. In general, we thus follow the strategy used by Cawley and Liu (2012) to identify mechanisms that could potentially be responsible for the effect of maternal employment on child overweight. In contrast to Cawley and Liu, we focus on the child's instead of the mother's time-use data. We try to estimate the causal effect of maternal full-time employment on the specific mechanisms using our IV approach.

Based on the Micorcensus data, we assess whether it matters when the mother works, exploring non-standard work schedules. However, in contrast to the investigation of the other mechanisms, we rely on the descriptive results obtained from simple OLS models as the instrument used is not predictive for these definitions of maternal non-standard employment. 


\section{Results}

\subsection{Descriptive Evidence}

In a first step, we illustrate the bivariate relationship between maternal employment and child (over)weight. Figure 2 (a) shows the distribution of child BMI by maternal employment status using the KiGGS data. While the distributions for children with not employed or part-time employed mothers are very similar, the distribution of children with full-time employed mothers is more humped and skewed to the right which indicates that children of full-time employed mothers tend to have a higher BMI. Figure 2 (b) shows the relationship between maternal working hours in deciles and the proportion of child overweight based on the Microcensus data. Apart from some irregularities, the figure shows that the proportion of child overweight increases with working hours decile. This increase is particularly markable in the last deciles which comprise maternal full-time employment.

Figure 2: Maternal employment and child (over)weight



(a) Source: KiGGS 2003-2006

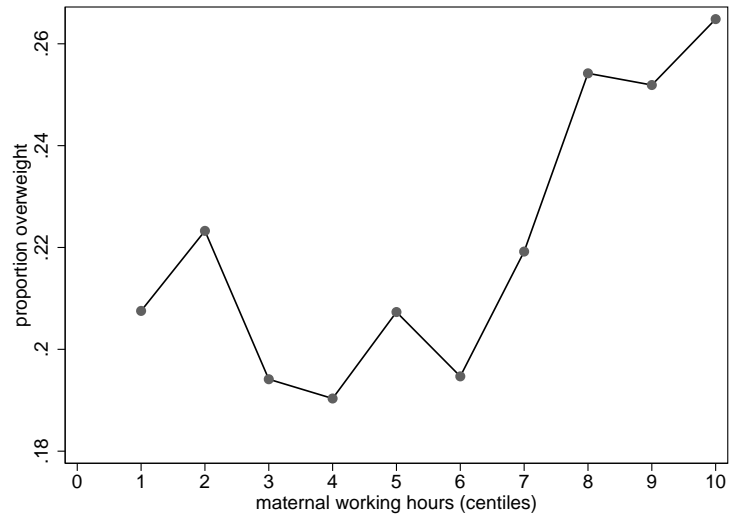

(b) Source: Microcensus 1999, 2003, 2005, 2009

\subsection{Estimates from OLS Regressions}

Table 1 reports the relationship between maternal employment and child BMI/overweight status. The different columns present the estimates when the different sets of control variables discussed in Section 3 are included successively. Panel A presents the results based on the KiGGS data. Maternal part-time employment is negatively related to the child's BMI, although this turns out to be insignificant in most specifications. Irrespective of the control variables included, part-time employment does not seem to be significantly related to child overweight. This might be due to the fact that there is no information about the exact number of working hours for the parttime employed mothers having a possible range of 1 to 30 hours/week. In contrast, maternal full-time employment is significantly related to a child's BMI in all specifications. The BMI of 
children with full-time working mothers is on average $0.35-0.53 \mathrm{~kg} / \mathrm{m}^{2}$ higher compared to children of not employed mothers. Accordingly, maternal full-time employment is associated with a 3.7-5.4 percentage point higher probability of the child being overweight, although this difference turns out to be significant in Column 4 and 5 only, once family characteristics are adjusted for.

The results based on the Microcensus (panel B) reveal a similar pattern regarding the relationship between maternal employment and child (over)weight. Maternal full-time employment is significantly related to a higher child overweight (3 percentage points) and a higher BMI (0.4 $\mathrm{kg} / \mathrm{m}^{2}$ ) when all sets of control variables are included. Maternal part-time employment is related to a significant lower child BMI and overweight probability in the first four specifications although this correlation reduces substantially the more observable characteristics are included. The fact that the estimates are smaller compared to the estimates obtained from the KiGGS data (panel A) might be due to the possible underestimation of BMI in parent/self-reported measures. Moreover, lacking information on certain child characteristics such as birth weight or conditions during pregnancy which we are not able to adjust for in the Microcensus might also be responsible for this difference.

In sum, the estimates on maternal full-time employment increase substantially the more observable differences/controls are taken into account, moving from the left hand to the right column. This might be due to the fact that these characteristics are (negatively) correlated with maternal full-time employment and/or child (over)weight. Our results are consistent with findings from studies using US or UK data that maternal employment is positively related to child BMI and overweight (e.g., von Hinke Kessler Scholder, 2008; Datar et al., 2014) and with Mahler (2007) who estimates a positive relationship for Germany. The model estimated in Column 5 is our preferred specification regarding the following analyses including all sets of control variables in order to minimize any potential bias, as discussed in Section 3.

Table 2 presents the OLS results regarding the relationship between different definitions of maternal employment on child weight, making use of the information on the usual hours worked in the Microcensus. For comparison, the first panel reports the results of the employment definition used in the previous analyses, comparable to Column (5) Table 1. In the second panel, we include maternal employment with different categories for different intensities of maternal working hours. In general, the estimates suggest that the relationship gradually increases with the rising intensity of working hours. The coefficients on overweight/BMI more than double moving to the category with 30 and more working hours per week. This finding again underlines that it is particularly maternal full-time employment that matters. Considering the number of working hours linearly divided by ten (third panel) suggests that conditional on being employed, each additional 10 hours of maternal work increase the child's probability to become overweight by 1.5 percentage points and the child's BMI by $0.14 \mathrm{~kg} / \mathrm{m}^{2}$. In general, the exploration of different definitions of maternal employment points towards a robust positive relationship between maternal (full-time) employment and child (over)weight.

As maternal part-time employment turns out to be of minor importance and does not differ 
Table 1: OLS estimates on maternal employment on child weight

\begin{tabular}{|c|c|c|c|c|c|c|}
\hline Dependent & & $(1)$ & $(2)$ & $(3)$ & $(4)$ & $(5)$ \\
\hline \multicolumn{7}{|l|}{ A: KiGGS } \\
\hline \multirow[t]{2}{*}{$\mathrm{BMI}$} & part-time & $\begin{array}{l}-0.2370 \\
(0.1553)\end{array}$ & $\begin{array}{l}-0.3024^{* *} \\
(0.1483)\end{array}$ & $\begin{array}{l}-0.2594^{*} \\
(0.1493)\end{array}$ & $\begin{array}{l}-0.0810 \\
(0.1499)\end{array}$ & $\begin{array}{l}0.0100 \\
(0.1426)\end{array}$ \\
\hline & full-time & $\begin{array}{l}0.3892^{* *} \\
(0.2087)\end{array}$ & $\begin{array}{l}0.3530^{*} \\
(0.2046)\end{array}$ & $\begin{array}{l}0.3897^{*} \\
(0.2046)\end{array}$ & $\begin{array}{l}0.5158^{* *} \\
(0.2005)\end{array}$ & $\begin{array}{l}0.5345^{* * *} \\
(0.1893)\end{array}$ \\
\hline \multirow[t]{5}{*}{ Overweight } & part-time & $\begin{array}{l}-0.0203 \\
(0.0186)\end{array}$ & $\begin{array}{l}-0.0185 \\
(0.0186)\end{array}$ & $\begin{array}{l}-0.0117 \\
(0.0186)\end{array}$ & $\begin{array}{l}0.0017 \\
(0.0190)\end{array}$ & $\begin{array}{l}0.0097 \\
(0.0186)\end{array}$ \\
\hline & full-time & $\begin{array}{l}0.0365 \\
(0.0256)\end{array}$ & $\begin{array}{l}0.0373 \\
(0.0264)\end{array}$ & $\begin{array}{l}0.0373 \\
(0.0263)\end{array}$ & $\begin{array}{l}0.0538^{* *} \\
(0.0263)\end{array}$ & $\begin{array}{l}0.0544^{* *} \\
(0.0255)\end{array}$ \\
\hline & Mean BMI & $\begin{array}{l}18.4871 \\
(0.0691)\end{array}$ & $\begin{array}{l}18.4871 \\
(0.0691)\end{array}$ & $\begin{array}{l}18.4871 \\
(0.0691)\end{array}$ & $\begin{array}{l}18.4871 \\
(0.0691)\end{array}$ & $\begin{array}{l}18.4871 \\
(0.0691)\end{array}$ \\
\hline & Mean overweight & $\begin{array}{l}0.2150 \\
(0.0083)\end{array}$ & $\begin{array}{l}0.2150 \\
(0.0083)\end{array}$ & $\begin{array}{l}0.2150 \\
(0.0083)\end{array}$ & $\begin{array}{l}0.2150 \\
(0.0083)\end{array}$ & $\begin{array}{l}0.2150 \\
(0.0083)\end{array}$ \\
\hline & $\mathrm{N}$ & 2,447 & 2,447 & 2,447 & 2,447 & 2,447 \\
\hline \multicolumn{7}{|c|}{ B: Microcensus } \\
\hline BMI & $\begin{array}{l}\text { part-time } \\
\text { full-time }\end{array}$ & $\begin{array}{l}-0.3962^{* * *} \\
(0.0364) \\
0.1429^{* * *} \\
(0.0500)\end{array}$ & $\begin{array}{l}-0.3849 \text { *** } \\
(0.0359) \\
0.0316 \\
(0.0517)\end{array}$ & $\begin{array}{l}-0.2084^{* * *} \\
(0.0361) \\
0.2224^{* * *} \\
(0.0515)\end{array}$ & $\begin{array}{l}-0.0876^{* * *} \\
(0.0366) \\
0.3503^{* * *} \\
(0.0523)\end{array}$ & $\begin{array}{l}-0.0276 \\
(0.0356) \\
0.3598^{* * *} \\
(0.0509)\end{array}$ \\
\hline \multirow[t]{8}{*}{ Overweight } & $\begin{array}{l}\text { part-time } \\
\text { full-time }\end{array}$ & $\begin{array}{l}-0.0511^{* * *} \\
(0.0044) \\
-0.0017 \\
(0.0061)\end{array}$ & $\begin{array}{l}-0.0448^{* * *} \\
(0.0045) \\
-0.0048 \\
(0.0063)\end{array}$ & $\begin{array}{l}-0.0257^{* * *} \\
(0.0045) \\
0.0160^{* *} \\
(0.0063)\end{array}$ & $\begin{array}{l}-0.0139^{* * *} \\
(0.0046) \\
0.0302^{* * *} \\
(0.0065)\end{array}$ & $\begin{array}{l}-0.0066 \\
(0.0045) \\
0.0312^{* * *} \\
(0.0063)\end{array}$ \\
\hline & Mean BMI & $\begin{array}{l}18.3235 \\
(0.0162)\end{array}$ & $\begin{array}{l}18.3235 \\
(0.0162)\end{array}$ & $\begin{array}{l}18.3235 \\
(0.0162)\end{array}$ & $\begin{array}{l}18.3235 \\
(0.0162)\end{array}$ & $\begin{array}{l}18.3235 \\
(0.0162)\end{array}$ \\
\hline & Mean overweight & $\begin{array}{l}0.2324 \\
(0.0020)\end{array}$ & $\begin{array}{l}0.2324 \\
(0.0020)\end{array}$ & $\begin{array}{l}0.2324 \\
(0.0020)\end{array}$ & $\begin{array}{l}0.2324 \\
(0.0020)\end{array}$ & $\begin{array}{l}0.2324 \\
(0.0020)\end{array}$ \\
\hline & $\mathrm{N}$ & 45,210 & 45,210 & 45,210 & 45,210 & 45,210 \\
\hline & child controls & & $\checkmark$ & $\checkmark$ & $\checkmark$ & $\checkmark$ \\
\hline & mother controls & & & $\checkmark$ & $\checkmark$ & $\checkmark$ \\
\hline & family controls & & & & $\checkmark$ & $\checkmark$ \\
\hline & parental BMI & & & & & $\checkmark$ \\
\hline
\end{tabular}

Note: ${ }^{*} \mathrm{p}<0.10,{ }^{* *} \mathrm{p}<0.05,{ }^{* * *} \mathrm{p}<0.01 ;$ Source: KiGGS 2003-2006; German Microcensus 1999, 2003, 2005, 2009

significantly from non-employment in the main specification, we collapse both categories in the following and thus focus on full-time employment vs. part-time/no employment in all further specifications. 
Table 2: OLS estimates on different definitions of maternal employment on child weight

\begin{tabular}{cllll}
\hline & & \multicolumn{2}{c}{ Dependent } & \\
\cline { 3 - 3 } emp. definition & Mean emp. & overweight & BMI & $\mathrm{N}$ \\
\hline B: Microcensus & & & & \\
\hline not employed & 0.3420 & reference & reference & 45,210 \\
& $(0.0022)$ & & & \\
part-time & 0.4878 & -0.0066 & -0.0276 & \\
& $(0.0024)$ & $(0.0045)$ & $(0.0356)$ & \\
full-time & 0.1702 & $0.0312^{* * *}$ & $0.3598^{* * *}$ & \\
& $(0.0018)$ & $(0.0063)$ & $(0.0509)$ & \\
\hline mwhours $\leq 10$ & 0.4685 & reference & reference & 45,210 \\
& $(0.0023)$ & & & \\
mwhours 10-20 & 0.2417 & $-0.0080^{*}$ & 0.0006 & \\
& $(0.0020)$ & $(0.0048)$ & $(0.0373)$ & \\
mwhours 20-30 & 0.1210 & $0.0110^{* *}$ & $0.1627^{* * *}$ & \\
& $(0.0015)$ & $(0.0063)$ & $(0.0483)$ & \\
mwhours $\geq 30$ & 0.1687 & $0.0340^{* * *}$ & $0.4008^{* * *}$ & \\
& $(0.0018)$ & $(0.0061)$ & $(0.0490)$ & \\
\hline mwhours $/ 10$ & 2.3031 & $0.0140^{* * *}$ & $0.1457^{* * *}$ & 30,037 \\
$(\mid$ employed $)$ & $(0.0074)$ & $(0.0021)$ & $(0.0166)$ & \\
\hline
\end{tabular}

Note: all models include a full range of control variables comparable to model (5), Table $1 ;{ }^{*} \mathrm{p}<0.10,{ }^{* *} \mathrm{p}<0.05,{ }^{* * *} \mathrm{p}<0.01$; Source: German Microcensus 1999, 2003, 2005, 2009

\subsection{Estimates from IV Regressions}

Although the OLS models suggest that maternal full-time employment is positively related to children's (over)weight status, the relationship might still occur due to unobserved characteristics of mothers and other non-causal explanations, which we are unable to control for. The main analysis thus aims to isolate the causal effect of maternal full-time employment on child (over)weight by applying the IV approach discussed in Section 4. Table 3 summarizes the results of the first stage of maternal full-time employment and the reduced form of BMI and overweight, again separated into panel A for the KiGGS data and panel B for the Microcensus data. In order to evaluate the robustness of our approach, we estimate three alternative specifications: (1) includes the number of younger siblings as continuous variable, (2) includes the number of younger siblings as a continuous variable but excludes families without younger siblings in the household, (3) includes the instrument non-parametrically as dummy variables taking children without younger siblings as reference group. The first stage (FS), which is shown in the first Column of each specification, regresses maternal employment on the instrument. The results indicate that the number of younger siblings in the household is strongly related to maternal full-time employment and that our approach therefore does not suffer from a weak instrument problem. Although the effect size varies slightly, the instrument is always negatively related to maternal full-time employment and estimates are significant 
at the 1 percent level regardless of the specification and the data source used. In accordance with the descriptive evidence presented in Figure 1, the estimates show a negative relationship: When the number of younger sibling increases, the probability of the mother to work full-time decreases. The causal interpretation of the IV estimate in the second stage rests upon the non-testable assumption that the instrument affects child (over)weight exclusively through maternal employment, the endogenous variable. We report the estimates of the reduced form (RF), i.e. the regression of the outcome on the instrument, in Column 2 for BMI and Column 3 for overweight. The estimates of the reduced form are consistently negative and almost always significantly different from zero, at least at the 10 percent level. For example, the coefficient in the first row for the KiGGS data (Microcensus) shows that with each additional younger sibling in the household, the BMI significantly decreases by $0.18 \mathrm{~kg} / \mathrm{m}^{2}\left(0.21 \mathrm{~kg} / \mathrm{m}^{2}\right)$. Accordingly, the probability of the child of interest to be overweight decreases by 2.3 (2.1) percentage points with each additional younger sibling in the household. The negative coefficients in both, the first stage and reduced form estimation, are in line with our theoretical predictions (Section 4).

Table 3: IV estimation on the effect of maternal full-time employment on child weight (first stage and reduced form)



Note: all models include a full range of control variables comparable to model (5), Table 1; FS refers to the first stage, RF to the reduced form estimations and $\mathrm{m}$.FT refers to maternal full-time employment; ${ }^{*} \mathrm{p}<0.10,{ }^{* *} \mathrm{p}<0.05,{ }^{* * *} \mathrm{p}<0.01 ;$ Source: KiGGS 2003-2006; German Microcensus 1999, 2003, 2005, 2009 
Table 4 shows the results from the second stage, again separated by data source and by the three IV-specifications to explore the sensitivity of our instrument. ${ }^{16}$ The first row of each specification presents the results for the continuous BMI variable while the second row presents the results for the overweight status indicator variable. The mean BMI and prevalence of overweight are included to better assess the dimension of the estimated effect. For comparison, Column (1) presents the OLS results which are comparable to the results reported in Table 1. It has to be mentioned that the coefficients slightly differ from those presented in Table 1 as the reference group for maternal full-time employment now also includes children with part-time employed mothers. Column (2) shows the second stage estimates, which reflect the supposed causal effect of maternal full-time employment on child overweight (for the subpopulation of mothers). As expected from the negative coefficients in the reduced form and first stage models, the estimates of the second stage are positive in all specifications and regardless of the data used. The effect is also significant except for the second specification based on the KiGGS data. Starting with the first specification (1), maternal full-time employment significantly increases child BMI by $1.9 \mathrm{~kg} / \mathrm{m}^{2}$ and the probability to be overweight by 25.04 percentage points, respectively in the KiGGS data (panel A). In relation to the mean values, this corresponds to an increase of about 140 percent. The proposed causal effect of mothers working full-time on child overweight (BMI) is more than five (three) times bigger compared to the OLS relationship, when the endogeneity is not taken into account. To illustrate, taking a 10-year old boy with average BMI and height as an example, the estimated effect would correspond to an increase in body weight of about $4 \mathrm{~kg}$ because of his mother's fulltime employment. The second stage results obtained from the Microcensus (panel B) are somewhat larger in magnitude compared and also suggest a higher effect of maternal employment on child BMI and overweight. The estimates point to a 28.15 percentage point higher overweight probability due to maternal employment. We interpret this finding as evidence for the robustness of our results, as the coefficients are again in a similar range compared to the results obtained from the KiGGS data.

The estimates of the alternative specifications of the instrument can be found in the second and third panel. Including the number of younger siblings as dummy variables (3) leads to very similar second stage results. When we exclude families without younger siblings in the household (2), we also obtain coefficients of comparable range for both, the KiGGS and the Microcensus data. While the estimates of this specification obtained from the Microcensus are also significantly different from zero, the estimates obtained from the KiGGS data become less precise and non-significant as the sample size is roughly halved. As the results appear to be robust regarding the specification used, we focus on the first specification by instrumenting maternal full-time employment by the continuous measure of the number of younger children in the household in the following.

Overall, the findings are again in line with previous studies using US and UK data which find

\footnotetext{
${ }^{16}$ See also Table A.3 in the Appendix for different estimation strategies of the IV model. The estimates in Column (6) are derived using a two-stage-residual-inclusion-approach in which the second stage includes the treatment and the fitted residual from a probit-estimated first stage in order to take the binary nature of the treatment into account (Wooldridge 2010, pp. 126-129; Terza et al. 2008).
} 
Table 4: IV estimation on the effect of maternal full-time employment on child weight (second stage)

\begin{tabular}{|c|c|c|c|c|c|}
\hline Model specification & Dependent & Mean & $\begin{array}{l}(1) \\
\text { OLS }\end{array}$ & $\begin{array}{l}(2) \\
2 \mathrm{SLS}\end{array}$ & $\mathrm{N}$ \\
\hline \multicolumn{6}{|l|}{ A: KiGGS } \\
\hline \multirow[t]{2}{*}{ (1) \# younger siblings } & BMI & $\begin{array}{l}18.4871 \\
(0.0691)\end{array}$ & $\begin{array}{l}0.5285^{* * *} \\
(0.1683)\end{array}$ & $\begin{array}{l}1.9116^{*} \\
(1.1012)\end{array}$ & 2,447 \\
\hline & overweight & $\begin{array}{l}0.2150 \\
(0.0083)\end{array}$ & $\begin{array}{l}0.0486^{* *} \\
(0.0227)\end{array}$ & $\begin{array}{l}0.2504^{*} \\
(0.1322)\end{array}$ & 2,447 \\
\hline \multirow[t]{2}{*}{ (2) \# younger siblings if ysib $>0$} & $\mathrm{BMI}$ & $\begin{array}{l}18.390 \\
(0.0888)\end{array}$ & $\begin{array}{l}0.4900^{* *} \\
(0.2490)\end{array}$ & $\begin{array}{l}2.9046 \\
(2.1718)\end{array}$ & 1,324 \\
\hline & overweight & $\begin{array}{l}0.1994 \\
(0.0110)\end{array}$ & $\begin{array}{l}0.0394 \\
(0.0352)\end{array}$ & $\begin{array}{l}0.3476 \\
(0.2729)\end{array}$ & 1,324 \\
\hline \multirow[t]{2}{*}{ (3) i.\# younger siblings } & $\mathrm{BMI}$ & $\begin{array}{l}18.4871 \\
(0.0691)\end{array}$ & $\begin{array}{l}0.5285^{* * *} \\
(0.1683)\end{array}$ & $\begin{array}{l}1.8270^{*} \\
(1.0668)\end{array}$ & 2,505 \\
\hline & overweight & $\begin{array}{l}0.2150 \\
(0.0083)\end{array}$ & $\begin{array}{l}0.0486^{* *} \\
(0.0227)\end{array}$ & $\begin{array}{l}0.2224^{*} \\
(0.1330)\end{array}$ & 2,505 \\
\hline \multicolumn{6}{|l|}{ B: Microcensus } \\
\hline \multirow[t]{2}{*}{ (1) \# younger siblings } & BMI & $\begin{array}{l}18.3235 \\
(0.0162)\end{array}$ & $\begin{array}{l}0.3765^{* * *} \\
(0.0454)\end{array}$ & $\begin{array}{l}2.8150^{* * *} \\
(0.3235)\end{array}$ & 45,210 \\
\hline & overweight & $\begin{array}{l}0.2324 \\
(0.0020)\end{array}$ & $\begin{array}{l}0.0353^{* * *} \\
(0.0056)\end{array}$ & $\begin{array}{l}0.2815^{* * *} \\
(0.0403)\end{array}$ & 45,210 \\
\hline \multirow[t]{2}{*}{ (2) \# younger siblings if ysib $>0$} & $\mathrm{BMI}$ & $\begin{array}{l}18.1638 \\
(0.0233)\end{array}$ & $\begin{array}{l}0.3776^{* * *} \\
(0.0773)\end{array}$ & $\begin{array}{l}2.5506^{* * * *} \\
(0.9751)\end{array}$ & 21,845 \\
\hline & overweight & $\begin{array}{l}0.2147 \\
(0.0028)\end{array}$ & $\begin{array}{l}0.0299^{* * *} \\
(0.0090)\end{array}$ & $\begin{array}{l}0.3257^{* * *} \\
(0.1202)\end{array}$ & 21,845 \\
\hline \multirow[t]{2}{*}{ (3) i.\# younger siblings } & BMI & $\begin{array}{l}18.3235 \\
(0.0162)\end{array}$ & $\begin{array}{l}0.3765^{* * *} \\
(0.0454)\end{array}$ & $\begin{array}{l}2.7150^{* * * *} \\
(0.4769)\end{array}$ & 45,210 \\
\hline & overweight & $\begin{array}{l}0.2324 \\
(0.0020)\end{array}$ & $\begin{array}{l}0.0353^{* * *} \\
(0.0056)\end{array}$ & $\begin{array}{l}0.2851^{* * * *} \\
(0.0592)\end{array}$ & 45,210 \\
\hline
\end{tabular}

Note: all models include a full range of control variables comparable to model $(5)$, Table $1 ;{ }^{*} \mathrm{p}<0.10,{ }^{* *} \mathrm{p}<0.05,{ }^{* * *} \mathrm{p}<0.01 ;$ Source: KiGGS 2003-2006; German Microcensus 1999, 2003, 2005, 2009 
slightly larger estimates for maternal employment when taking the possible endogeneity of maternal employment into account (Anderson et al., 2003; von Hinke Kessler Scholder, 2008; Bishop, 2011). This suggests that mothers select themselves into full-time employment due to some unobserved characteristics that promote child health, like effort or ability. Another reason for the downward bias of the OLS estimates could be that maternal full-time employment is not measured accurately. Commuting hours or other time constraints involved with maternal full-time employment might be not captured by the contractually agreed employment definition, as reported in the data used. However, the effects obtained from our IV approach become large in magnitude relative to the OLS models that assume exogeneity of maternal employment. It has to be considered that the instrumental variable approach estimates a local average treatment effect and allows the interpretation of the identified effects only for the narrow subpopulation of compliers (Angrist and Pischke, 2009). In our case, the compliant population consists of mothers whose decision to work was influenced by the number of younger siblings in the household. These mothers might have certain characteristics or make a huge effort that accounts for the large estimates. The increase in the effect size might also result from an invalid instrument, i.e. the instrument correlates with factors that are also related to the child's weight status, as discussed in Section 4.1. For example, one might argue that an additional younger child changes the parental behavior which directly affects the weight status of the older child. If at all, we believe that an instrument invalidity of this type likely results in a downward bias. That is, the child is less likely to be overweight as the mother might be more engaged to ensure healthy food and living if she has more than one child. Obtaining large IV estimates is not unusual. Morrill (2011) also finds that estimates increase by roughly 200 percent when applying a similar IV approach using the younger sibling's kindergarten eligibility as instrument for maternal employment. Whereas the estimates are not directly comparable as Morrill focuses on different outcomes for adverse child health, like the probability of an overnight hospitalization and not on child overweight, this still supports the credibility of our estimates.

\subsection{Robustness Analyses}

We next test the robustness of our estimates by excluding certain children from the analyses according to the theoretical discussion in Section 4.1 and using an alternative definition of the instrument in the Microcensus data. Based on the restricted samples, we repeat the analyses of the main IV specification (1) presented in Table 4. First (1), we exclude children with non-working mothers from our analyses. Therefore we focus on the variation in hours worked, full-time versus part-time, which enables us to estimate the effect of maternal employment on child overweight at the intensive margin. That way we aim to mitigate the potential bias resulting from selection into employment. Table 5 presents the results of the OLS model, the first stage (FS), the reduced form (RF) and the 2SLS estimates. The OLS estimates for BMI (KiGGS: 0.5176, Microcensus: 0.3914) and overweight (KiGGS: 0.0474, Microcensus: 0.0385) are still significant and very similar in magnitude compared to the non-restricted analyses. The results of the first stage are slightly smaller but still significant, indicating that each additional younger children in the household 
decreases the employed mother's probability to work full-time by 7.92 percentage points in the KiGGS data and 6.3 percentage points in the Microcensus data. Compared to the main analyses presented in Section 5.3, the estimates of the second stage are slightly smaller for the KiGGS data but somewhat larger for the Microcensus data although quantitatively still in a similar range. However, whereas the estimates are still significant for the Microcensus data, the estimates turn out to be not significantly different from zero in the KiGGS data. This likely results from the lack of statistical power due to the restricted sample size, as the standard errors become very large. We conclude that the IV results presented in Section 5.3 appear to be hardly affected by the selection into employment.

Table 5: Robustness analyses

\begin{tabular}{|c|c|c|c|c|c|c|c|}
\hline Model specification & Dependent & Mean & $\begin{array}{l}(1) \\
\text { OLS }\end{array}$ & $\begin{array}{l}(2) \\
\text { FS }\end{array}$ & $\begin{array}{l}(3) \\
\mathrm{RF}\end{array}$ & $\begin{array}{l}(4) \\
2 S L S\end{array}$ & $\mathrm{~N}$ \\
\hline \multicolumn{8}{|l|}{ A: KiGGS } \\
\hline \multicolumn{8}{|c|}{ (1) FT vs. PT: non-employed mothers excluded } \\
\hline & $\mathrm{BMI}$ & $\begin{array}{l}18.4631 \\
(0.0838)\end{array}$ & $\begin{array}{l}0.5176^{* * *} \\
(0.1833)\end{array}$ & $\begin{array}{l}-0.0792^{* * *} \\
(0.0197)\end{array}$ & $\begin{array}{l}-0.0816 \\
(0.1492)\end{array}$ & $\begin{array}{l}1.0303 \\
(1.8766)\end{array}$ & 1,656 \\
\hline & overweight & $\begin{array}{l}0.2132 \\
(0.0101)\end{array}$ & $\begin{array}{l}0.0474^{*} \\
(0.0243)\end{array}$ & $\begin{array}{l}-0.0792^{* * *} \\
(0.0197)\end{array}$ & $\begin{array}{l}-0.0107 \\
(0.0189)\end{array}$ & $\begin{array}{l}0.2149 \\
(0.2401)\end{array}$ & 1,656 \\
\hline \multicolumn{8}{|c|}{ (2) 1 st born and children without older siblings excluded } \\
\hline & BMI & $\begin{array}{l}18.5441 \\
(0.0933)\end{array}$ & $\begin{array}{l}0.3811^{*} \\
(0.2113)\end{array}$ & $\begin{array}{l}-0.0888^{* * *} \\
(0.0153)\end{array}$ & $\begin{array}{l}-0.1375 \\
(0.1609)\end{array}$ & $\begin{array}{l}1.593 \\
(1.7957)\end{array}$ & 1,446 \\
\hline & overweight & $\begin{array}{l}0.2248 \\
(0.0110)\end{array}$ & $\begin{array}{l}0.0392 \\
(0.0280)\end{array}$ & $\begin{array}{l}-0.0888^{* * *} \\
(0.0153)\end{array}$ & $\begin{array}{l}-0.0233 \\
(0.0171)\end{array}$ & $\begin{array}{l}0.2628 \\
(0.1945)\end{array}$ & 1,446 \\
\hline \multicolumn{8}{|l|}{ B: Microcensus } \\
\hline \multicolumn{8}{|c|}{ (1) FT vs. PT: non-employed mothers excluded } \\
\hline & $\mathrm{BMI}$ & $\begin{array}{l}18.23573 \\
(0.0024)\end{array}$ & $\begin{array}{l}0.3914^{* * *} \\
(0.0485)\end{array}$ & $\begin{array}{l}-0.0628^{* * *} \\
(0.0040)\end{array}$ & $\begin{array}{l}-0.2311^{* * *} \\
(0.0313)\end{array}$ & $\begin{array}{l}3.6785^{* * *} \\
(0.5425)\end{array}$ & 29,748 \\
\hline & overweight & $\begin{array}{l}0.2193 \\
(0.024)\end{array}$ & $\begin{array}{l}0.0385^{* * *} \\
(0.0061)\end{array}$ & $\begin{array}{l}-0.0628^{* * *} \\
(0.0040)\end{array}$ & $\begin{array}{l}-0.0204^{* * *} \\
(0.0040)\end{array}$ & $\begin{array}{l}0.3248^{* * * *} \\
(0.0659)\end{array}$ & 29,748 \\
\hline \multicolumn{8}{|c|}{ (2) 1 st born and children without older siblings excluded } \\
\hline & $\mathrm{BMI}$ & $\begin{array}{l}18.4485 \\
(0.0225)\end{array}$ & $\begin{array}{l}0.3394^{* * *} \\
(0.0638)\end{array}$ & $\begin{array}{l}-0.0616^{* * *} \\
(0.0038)\end{array}$ & $\begin{array}{l}-0.1221^{* * *} \\
(0.0356)\end{array}$ & $\begin{array}{l}1.9819^{* * *} \\
(0.5852)\end{array}$ & 22,367 \\
\hline & overweight & $\begin{array}{l}0.2475 \\
(0.0029)\end{array}$ & $\begin{array}{l}0.0389^{* * *} \\
(0.0083)\end{array}$ & $\begin{array}{l}-0.0616^{* * *} \\
(0.0038)\end{array}$ & $\begin{array}{l}-0.0152^{* * *} \\
(0.0046)\end{array}$ & $\begin{array}{l}0.2462^{* * *} \\
(0.0761)\end{array}$ & 22,367 \\
\hline \multicolumn{8}{|c|}{ (3) alternative Instrument: \# younger siblings $<6$ years of age } \\
\hline & BMI & $\begin{array}{l}18.3235 \\
(0.0162)\end{array}$ & $\begin{array}{l}0.3765^{* * *} \\
(0.0454)\end{array}$ & $\begin{array}{l}-0.0635^{* * *} \\
(0.0036)\end{array}$ & $\begin{array}{l}-0.1625^{* * *} \\
(0.0347)\end{array}$ & $\begin{array}{l}2.5579 * * * \\
(0.5578)\end{array}$ & 45,210 \\
\hline & overweight & $\begin{array}{l}0.2324 \\
(0.0020)\end{array}$ & $\begin{array}{l}0.0353^{* * *} \\
(0.0056)\end{array}$ & $\begin{array}{l}-0.0635^{* * *} \\
(0.0036)\end{array}$ & $\begin{array}{l}-0.0182^{* * *} \\
(0.0042)\end{array}$ & $\begin{array}{l}0.2862^{* * *} \\
(0.0677)\end{array}$ & 45,210 \\
\hline
\end{tabular}

Note: all models include a full range of control variables comparable to model (5), Table 1; FS refers to the first stage, RF to the reduced form ans 2SLS to the second stage estimations, m.FT refers to the coefficient on maternal full-time employment; ${ }^{*} \mathrm{p}<0.10,{ }^{* *} \mathrm{p}<0.05,{ }^{* * *} \mathrm{p}<0.01 ;$ Source: KiGGS 2003-2006; German Microcensus 1999, 2003, 2005, 2009

In a second sensitivity analyses (2), first-born children and children without older siblings in 
the household are excluded in order to assess whether the IV estimates of maternal employment on child overweight are driven by the fact that first-born children are at a higher risk to become overweight. The estimates become slightly smaller and in the KiGGS data, the coefficients are again estimated with reduced precision. However, as the coefficients are still quantitatively comparable to the estimates obtained from the main estimations in Table 4, the main results are unlikely to be driven by the correlation between being the first-born child and overweight.

In a third step (3), we exploit the Microcensus data in order to check the robustness of our instrumental variable approach as we are able to determine the youngest sibling's age. In Germany, school attendance becomes compulsory at the age of six. We thus instrument maternal full-time employment by the number of younger siblings below this age. In accordance with the results previously obtained, we again find that the instrument is highly predictive for maternal employment. The results obtained from the second stage are also very similar to the instrument specification previously used.

\subsection{Mechanisms}

We further explore which mechanisms might be responsible for the positive effect of maternal fulltime employment on child (over)weight. For the KiGGS data, Table 6 presents the OLS and IV estimates of the effect maternal full-time employment on different outcomes which might theoretically serve as mechanisms in the relationship between maternal employment and child over(weight). Thus, each row presents a regression with another dependent variable. Concerning dietary habits, the results are twofold. Whereas we do not find any significant relation between maternal full-time employment and eating sweets or chocolate at least once a day, or eating junk food at least once a week, we do find some evidence regarding other dietary habits. Although not indicated by the OLS models, maternal full-time employment significantly reduces the probability that the child eats vegetables and fruits at least once a day by 58 and 41 percentage points. Moreover, children with full-time working mothers have a 42 percentage point higher likelihood to drink sugary soda at least once a day. They are also more likely (32 percentage point) to consume prepared meals once a week compared to children of not employed or part-time employed mothers. This finding could be a hint that full-time employed mothers spend less time preparing food freshly and draw on prepared meals instead. These findings are also in line with previous literature exploring the mechanisms using US data which found that maternal employment is related to unhealthy dietary habits (Bauer et al., 2012; Cawley and Liu, 2012; Datar et al., 2014).

With respect to the child's activities we find no significant difference in the probability to exercise at least three times a week between children of full-time employed mothers on the one hand and children of part-time or not employed mothers on the other hand. While the IV estimate suggests that children of full-time employed mothers are less likely to exercise at least three times a week, this turns out to be insignificant. However, we find some evidence that children of full-time employed mothers are significantly more likely to engage in sedentary behavior as the IV estimate suggest a 47 percentage point increase in the probability to watching TV at least one hour a day. 
With regard to the probability of playing video games at least 1 hour a day we find a significant 49 percentage point, and thus a 125 percent, increase due to maternal full-time employment.

Apart from the child's activity and nutritional behavior which are directly linked to childhood overweight, we also explore mechanisms that might be indirectly related to child overweight, for example through psychological mechanisms. However, we do not find much evidence that these factors could account for the positive relationship between maternal employment and child overweight, as they are not related to maternal employment in the expected direction. While the amount of sleep is not significantly related to maternal full-time employment, the probability of having sleep problems is significantly lower (40 percentage points) among children with full-time employed mothers. Similarly, children of full-time employed mothers tend to experience significantly more family support. No significant difference can be found regarding the probability to undertake family activities often. Only the probability to have rigid rules within the family is significantly lower (45 percentage points) among families with full-time employed mothers. This could indicate that having few rules within the family, for example concerning eating or watching TV, might account for the relationship between maternal employment and child overweight.

Based on the Microcensus data, we finally assess whether it matters when the mother works, exploring non-standard work schedules relying on simple OLS models. Table 7 reports the results on the relationship between different maternal non-standard work schedules and child overweight/BMI. Children of mothers who work on Saturdays at least sometimes face a significantly higher overweight probability of 2.4 percentage points. Working on Sundays, at nights and in the evening point to a very similar significant relationship, although these correlations appear to be somewhat weaker. Interestingly, we do not find a significant relationship between maternal teleworking and child overweight. This is in line with Rapoport and Le Bourdais (2008) who have previously shown that teleworking is in general related to more time spent with different types of domestic work. Taking these findings together, our results suggests that it is the reduced maternal time spent with the child that might account for the relationship between maternal employment and child overweight. However, this might only be interpreted as a cautious hint for a possible mechanism, as we are unable to explore a causal link.

\section{Conclusions}

The aim of our study was to explore the (causal) relationship between maternal employment and preadolescent overweight in Germany. In order to address the selection into maternal full-time employment, we use an instrumental variable strategy using the number of younger siblings in the household as an instrument. Taking the endogeneity into account, estimates become larger and suggest that maternal full-time employment increases the probability of the child being overweight by 25 percentage points. Thus, exploring the simple correlation between maternal employment and child overweight is likely to understate the effect as mothers may select themselves into 
Table 6: The effect of maternal full-time employment on possible mechanisms (KiGGS)

\begin{tabular}{|c|c|c|c|c|c|}
\hline & Dependent Variable & $\mathrm{N}$ & Mean & OLS & 2SLS \\
\hline \multicolumn{6}{|c|}{ A: KiGGS } \\
\hline \multirow{14}{*}{ 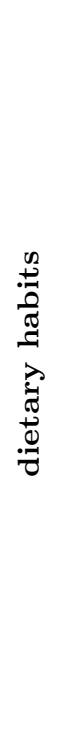 } & vegetables at least once per day & 2,359 & 0.2904 & 0.0024 & $-0.5754^{* * *}$ \\
\hline & & & $(0.0093)$ & $(0.0261)$ & $(0.1850)$ \\
\hline & fruits at least once per day & 2,359 & 0.5286 & 0.0176 & $-0.4135^{* *}$ \\
\hline & & & $(0.0102)$ & $(0.0273)$ & $(0.1824)$ \\
\hline & soda drinks at least once per day & 2,376 & 0.3157 & $0.0629 * *$ & $0.4229 * * *$ \\
\hline & & & $(0.0095)$ & $(0.0268)$ & $(0.1572)$ \\
\hline & sweets at least once per day & 2,371 & 0.1987 & -0.0311 & -0.0502 \\
\hline & & & $(0.0082)$ & $(0.0215)$ & $(0.1460)$ \\
\hline & chocolate at least once per day & 2,369 & 0.1490 & 0.0090 & 0.1546 \\
\hline & & & $(0.0073)$ & $(0.0204)$ & $(0.1285)$ \\
\hline & junkfood at least once per week & 2,369 & 0.1173 & $0.0455^{* *}$ & -0.0041 \\
\hline & & & $(0.0066)$ & $(0.0197)$ & $(0.1156)$ \\
\hline & prepared food at least once per week & 2,354 & 0.1529 & 0.0051 & $0.3194^{* *}$ \\
\hline & & & $(0.0074)$ & $(0.0210)$ & $(0.1300)$ \\
\hline \multirow{6}{*}{  } & exercise at least 3 times per week & 2,426 & 0.4217 & 0.0006 & -0.1313 \\
\hline & & & $(0.0100)$ & $(0.0248)$ & $(0.1549)$ \\
\hline & watching TV at least $1 \mathrm{~h} /$ day & 2,395 & 0.9253 & $0.0333^{* *}$ & $0.4747^{* * *}$ \\
\hline & & & $(0.0054)$ & $(0.0138)$ & $(0.1249)$ \\
\hline & video games at least $1 \mathrm{~h} /$ day & 2,371 & 0.3893 & $0.0830 * * *$ & $0.4873^{* * *}$ \\
\hline & & & $(0.0100)$ & $(0.0273)$ & $(0.1628)$ \\
\hline \multirow{4}{*}{$\begin{array}{l}\frac{D}{0} \\
\frac{0}{n}\end{array}$} & hours of sleep per day & 2,426 & 9.4378 & 0.0126 & 0.2642 \\
\hline & & & $(0.0224)$ & $(0.0675)$ & $(0.3732)$ \\
\hline & having problems with sleep & 2,417 & 0.2011 & -0.0117 & $-0.3965^{* *}$ \\
\hline & & & $(0.0082)$ & $(0.0223)$ & $(0.1576)$ \\
\hline \multirow{6}{*}{ 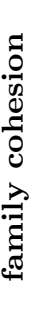 } & undertake family activities often & 2,387 & 0.6355 & 0.0377 & 0.2835 \\
\hline & & & $(0.0099)$ & $(0.0267)$ & $(0.1775)$ \\
\hline & rigid rules within the family & 2,388 & 0.5406 & -0.0290 & $-0.4526^{* *}$ \\
\hline & & & $(0.0102)$ & $(0.0285)$ & $(0.1874)$ \\
\hline & family support index $[0 ; 100]$ & 2,447 & 65.3215 & 0.0849 & $9.1483^{*}$ \\
\hline & & & $(0.2526)$ & $(0.7411)$ & $(4.7844)$ \\
\hline
\end{tabular}

Note: each coefficient belongs to a separate regression with the corresponding mechanism variable as dependent; all models include a full range of control variables comparable to model $(5)$, Table $1 ;{ }^{*} \mathrm{p}<0.10,{ }^{* *} \mathrm{p}<0.05,{ }^{* * *} \mathrm{p}<0.01 ;$ Source: KiGGS 2003-2006 
Table 7: OLS estimates of maternal non-standard work on child weight

\begin{tabular}{lllll}
\hline & & \multicolumn{2}{c}{ Dependent } & \\
\cline { 3 - 3 } maternal non-standard work & Mean work & BMI & overweight & N \\
\hline B: Microcensus & & & & \\
\hline work on Saturdays & 0.4079 & $0.1823^{* * *}$ & $0.0240^{* * *}$ & 29,971 \\
& $(0.0028)$ & $(0.0375)$ & $(0.0048)$ & \\
work on Sundays/Holidays & 0.2357 & $0.1477^{* * *}$ & $0.0157^{* * *}$ & 29,970 \\
& $(0.0025)$ & $(0.0435)$ & $(0.0056)$ & \\
work at nights (11pm-6am) & 0.0913 & $0.1164^{*}$ & $0.0143^{*}$ & 29,954 \\
& $(0.0017)$ & $(0.0644)$ & $(0.0083)$ & \\
work in the evening (6pm-11am) & 0.3196 & $0.0843^{* *}$ & $0.0115^{* *}$ & 29,962 \\
& $(0.0027)$ & $(0.0389)$ & $(0.0050)$ & \\
work at home & 0.1481 & -0.0483 & -0.0033 & 29,985 \\
& $(0.0021)$ & $(0.0504)$ & $(0.0065)$ & \\
\hline
\end{tabular}

Note: nonstandard work $=1$ if sometimes, regularly, and often; nonstandard work $=0$ if never; all all models include a full range of control variables comparable to model (5), Table $1 ;{ }^{*} \mathrm{p}<0.10,{ }^{* *} \mathrm{p}<0.05,{ }^{* * *} \mathrm{p}<0.01$; Source: German Microcensus 1999, 2003, 2005, 2009

full-time employment due to unobserved characteristics (e.g., maternal effort, ability) that promote child health. This finding is robust to several sensitivity analyses based on different sample selection criteria and instrument definitions. Although these estimates sometimes lack precision, the direction and magnitude point to the same direction, which reinforces the validity of our instrument and credibility of our results. Our findings are based on two different representative data sources and are very similar which further confirms the robustness of our findings. In order to contribute to previous research, we explore several pathways like dietary habits, activity behavior, sleep and family cohesion which might account for this relationship. We find some evidence that maternal full-time employment is related to unhealthy dietary habits, sedentary behavior and a fewer probability of rigid family rules that might be relevant mechanisms through which maternal employment encourages child overweight. Our results provide no evidence that the amount of sleep could mediate the relationship as previously suggested by Ziol-Guest (2014). We also find no evidence that psychological mechanisms, such as low family cohesion, do account for this relationship. However, against the background that we use cross-sectional data, it has to be considered that the child's overweight status, maternal employment status and various mechanisms are measured contemporaneously. Thus, our results do not indicate any long-term consequences of maternal employment for child weight and future research should not ignore those pathways which seem to be of minor importance in this cross-sectional framework (c.f. Fertig et al., 2009). 


\section{References}

Anderson, P. M., Butcher, K. F. and Levine, P. B. (2003). Maternal employment and overweight children, Journal of Health Economics 22(3): 477-504.

URL:http://www.sciencedirect.com/science/article/pii/S0167629603000225

Angrist, J. D. (2001). Estimation of limited dependent variable models with dummy endogenous regressors, Journal of Business \& Economic Statistics 19(1): 2-28.

Angrist, J. D. and Pischke, J.-S. (2009). Mostly harmless econometrics: An empiricist's companion, Princeton University Press, Princeton.

Aughinbaugh, A. and Gittleman, M. (2004). Maternal employment and adolescent risky behavior, Journal of Health Economics 23(4): 815-838.

URL:http://www.sciencedirect.com/science/article/pii/S0167629604000542

Baron, R. M. and Kenny, D. A. (1986). The moderator-mediator variable distinction in social psychological research: Conceptual, strategic, and statistical considerations, Journal of Personality and Social Psychology 51(6): 1173-1182.

Bauer, K. W., Hearst, M. O., Escoto, K., Berge, J. M. and Neumark-Sztainer, D. (2012). Parental employment and work-family stress: Associations with family food environments, Social Science Es Medicine 75(3): 496-504.

Bishop, J. (2011). The effect of maternal employment on youth overweight in australia, Economic Record 87: 92-104.

URL:http://dx.doi.org/10.1111/j.1475-4932.2011.00747.x

Bullock, J. G., Green, D. P. and Ha, S. E. (2010). Yes, but what's the mechanism? (don't expect an easy answer), Journal of Personality and Social Psychology 98(4): 550-558.

Cawley, J. (2011). The Oxford handbook of the social science of obesity, Oxford University Press, New York.

Cawley, J. and Liu, F. (2012). Maternal employment and childhood obesity: A search for mechanisms in time use data, Economics \& Human Biology 10(4): 352-364.

URL:http://www.sciencedirect.com/science/article/pii/S1570677X12000652

Chen, X., Beydoun, M. A. and Wang, Y. (2008). Is sleep duration associated with childhood obesity? A systematic review and meta-analysis, Obesity (Silver Spring, Md.) 16(2): 265-274.

Cole, T. J., Bellizzi, M. C., Flegal, K. M. and Dietz, W. H. (2000). Establishing a standard definition for child overweight and obesity worldwide: international survey, BMJ (Clinical research ed.) 320(7244): 1240-1243. 
Datar, A., Nicosia, N. and Shier, V. (2014). Maternal work and children's diet, activity, and obesity, Social Science \&f Medicine 107: 196-204.

Destatis (2012). Geburten in Deutschland, Report 2012, Statistisches Bundesamt, Wiesbaden.

Dunifon, R., Kalil, A., Crosby, D. A. and Su, J. H. (2013). Mothers' night work and children's behavior problems, Developmental Psychology 49(10): 1874-1885.

Fertig, A., Glomm, G. and Tchernis, R. (2009). The connection between maternal employment and childhood obesity: inspecting the mechanisms, Review of Economics of the Household 7(3): 227255 .

URL:http://dx.doi.org/10.1007/s11150-009-9052-y

Garcia, E., Labeaga, J. M. and Ortega, C. (2006). Maternal employment and childhood obesity in spain, Working Paper 2006-17, FEDEA, Madrid.

Goodman, E., Hinden, B. R. and Khandelwal, S. (2000). Accuracy of teen and parental reports of obesity and body mass index, Pediatrics 106(1 Pt 1): 52-58.

Greve, J. (2011). New results on the effect of maternal work hours on children's overweight status: Does the quality of child care matter?, Labour Economics 18(5): 579-590.

URL:http://www.sciencedirect.com/science/article/pii/S0927537111000340

Gwozdz, W., Sousa-Poza, A., Reisch, L. A., Ahrens, W., Eiben, G., Fernandéz-Alvira, J. M., Hadjigeorgiou, C., Henauw, Eva Kovács, Fabio Lauria, Toomas Veidebaum, Garrath Williams and Karin Bammann (2013). Maternal employment and childhood obesity - a european perspective, Journal of Health Economics 32(4): 728-742.

URL:http://www.sciencedirect.com/science/article/pii/S0167629613000520

Kromeyer-Hauschild, K., Wabitsch, M., Kunze, D., Geller, F., Geiß, H. C., Hesse, V., Hippel, A. v., Jaeger, U., Johnsen, D., Korte, W., Menner, K., Müller, G., Müller, J. M., NiemannPilatus, A., Remer, T., Schaefer, F., Wittchen, H.-U., Zabransky, S., Zellner, K., Ziegler, A. and Hebebrand, J. (2001). Perzentile für den Body-mass-Index für das Kindes- und Jugendalter unter Heranziehung verschiedener deutscher Stichproben, Monatsschrift Kinderheilkunde 149(8): 807818.

URL:http://dx.doi.org/10.1007/s001120170107

Kurth, B.-M., Kamtsiuris, P., Hölling, H., Schlaud, M., Dölle, R., Ellert, U., Kahl, H., Knopf, H., Lange, M., Mensink, G. B., Neuhauser, H., Rosario, A. S., Scheidt-Nave, C., Schenk, L., Schlack, R., Stolzenberg, H., Thamm, M., Thierfelder, W. and Wolf, U. (2008). The challenge of comprehensively mapping children's health in a nation-wide health survey: design of the german kiggs-study, BMC Public Health 8: 196. 
Li, C., Goran, M. I., Kaur, H., Nollen, N. and Ahluwalia, J. S. (2007). Developmental trajectories of overweight during childhood: role of early life factors, Obesity (Silver Spring, Md.) 15(3): 760771.

Mahler, P. (2007). I'm not fat, just too short for my weight: Family child care and obesity in germany, Working Paper 070\%, Socioeconomic Institute, University of Zurich, Zurich.

URL:http://hdl.handle.net/10419/76202

Miller, D. P. (2011). Maternal work and child overweight and obesity: The importance of timing, Journal of Family and Economic Issues 32(2): 204-218.

URL:http://dx.doi.org/10.1007/s10834-010-9244-x

Morrill, M. S. (2011). The effects of maternal employment on the health of school-age children, Journal of Health Economics 30(2): 240-257.

Morrissey, T. W., Dunifon, R. E. and Kalil, A. (2011). Maternal employment, work schedules, and children's body mass index, Child Development 82(1): 66-81.

URL:http://dx.doi.org/10.1111/j.1467-8624.2010.01541.x

Möser, A., Chen, S. E., Jilcott, S. B. and Nayga, R. M. (2012). Associations between maternal employment and time spent in nutrition-related behaviours among german children and mothers, Public Health Nutrition 15(7): 1256-1261.

Nie, P. and Sousa-Poza, A. (2014). Maternal employment and childhood obesity in china: evidence from the china health and nutrition survey, Applied Economics 46(20): 2418-2428.

Rapoport, B. and Le Bourdais, C. (2008). Parental time and working schedules, Journal of Population Economics 21(4): 903-932.

URL:http://dx.doi.org/10.1007/s00148-007-0147-6

Reinhold, S. and Jürges, H. (2012). Parental income and child health in germany, Health Economics 21(5): 562-579.

URL:http://dx.doi.org/10.1002/hec.1732

Ruhm, C. J. (2004). Parental employment and child cognitive development, Journal of Human Resources XXXIX(1): 155-192.

Ruhm, C. J. (2008). Maternal employment and adolescent development, Labour Economics 15(5): 958-983.

URL:http://www.sciencedirect.com/science/article/pii/S0927537107000656

Terza, J. V., Basu, A. and Rathouz, P. J. (2008). Two-stage residual inclusion estimation: addressing endogeneity in health econometric modeling, Journal of Health Economics 27(3): 531-543.

von Hinke Kessler Scholder, S. (2008). Maternal employment and overweight children: does timing matter?, Health Economics 17(8): 889-906. 
Wooldridge, J. M. (2010). Econometric analysis of cross section and panel data, 2nd ed. edn, MIT Press, Cambridge and Mass.

Ziol-Guest, K. M. (2014). A commentary on "maternal work and children's diet, activity, and obesity", Social Science \& Medicine 107: 205-208.

Ziol-Guest, K. M., Dunifon, R. E. and Kalil, A. (2013). Parental employment and children's body weight: Mothers, others, and mechanisms, Social Science $\&$ Medicine 95: 52-59. 


\section{Appendix}

Table A.1: Summary statistics of the main variables

\begin{tabular}{|c|c|c|c|c|c|c|c|c|}
\hline & & & \multicolumn{3}{|c|}{ A: KiGGS } & \multicolumn{3}{|c|}{ B: Microcensus } \\
\hline & & & $\begin{array}{c}\text { Not } \\
\text { Overweight }\end{array}$ & Overweight & Difference & $\begin{array}{c}\text { Not } \\
\text { Overweight }\end{array}$ & Overweight & Difference \\
\hline \multirow{4}{*}{ 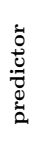 } & \multirow[t]{3}{*}{ m' employment } & none & 0.321 & 0.328 & -0.007 & 0.331 & 0.379 & $-0.048^{* * *}$ \\
\hline & & part-time & 0.511 & 0.462 & $0.049^{* *}$ & 0.504 & 0.434 & $0.071^{* * *}$ \\
\hline & & full-time & 0.167 & 0.209 & $-0.042^{* *}$ & 0.165 & 0.187 & $-0.022^{* * *}$ \\
\hline & \multicolumn{2}{|c|}{ m'working hours/week } & & & & 22.74 & 24.09 & $-1.355^{* * *}$ \\
\hline \multirow{12}{*}{  } & \multirow{12}{*}{ interview } & girl & 0.471 & 0.492 & -0.021 & 0.507 & 0.431 & $0.076^{* * *}$ \\
\hline & & age & 10.92 & 11.01 & -0.090 & 10.54 & 10.44 & $0.101^{* * *}$ \\
\hline & & breastfed & 0.806 & 0.728 & $0.078^{* * *}$ & \multirow{10}{*}{0.838} & \multirow{10}{*}{0.814} & \multirow{10}{*}{$0.024^{* * *}$} \\
\hline & & birthweight & 3364 & 3496 & $-132.6^{* * *}$ & & & \\
\hline & & West-Germany & 0.697 & 0.696 & -0.001 & & & \\
\hline & & rural & 0.239 & 0.262 & -0.023 & & & \\
\hline & & small-town & 0.286 & 0.274 & 0.012 & & & \\
\hline & & town & 0.284 & 0.285 & 0.001 & & & \\
\hline & & city & 0.192 & 0.179 & 0.013 & & & \\
\hline & & mother & 0.913 & 0.892 & 0.021 & & & \\
\hline & & father & 0.049 & 0.067 & -0.017 & & & \\
\hline & & parents & 0.037 & 0.040 & -0.003 & & & \\
\hline \multirow{15}{*}{  } & \multirow{15}{*}{$\begin{array}{r}\text { father } \\
\text { hhincome }\end{array}$} & mother's age & 38.92 & 38.69 & 0.226 & 39.29 & 38.77 & $0.522^{* * *}$ \\
\hline & & weight gain & 13.11 & 13.50 & -0.392 & & & \\
\hline & & smoke $^{a}$ & 0.126 & 0.217 & $-0.091^{* * *}$ & 0.254 & 0.336 & $-0.081^{* * *}$ \\
\hline & & drink & 0.146 & 0.106 & $0.039^{* *}$ & & & \\
\hline & & employed & 0.924 & 0.861 & $0.063^{* * *}$ & 0.918 & 0.878 & $0.040^{* * *}$ \\
\hline & & low & 0.280 & 0.380 & $-0.101^{* * *}$ & 0.270 & 0.363 & $-0.093^{* * *}$ \\
\hline & & medium & 0.417 & 0.399 & 0.018 & 0.417 & 0.389 & $0.028^{* * *}$ \\
\hline & & high & 0.303 & 0.221 & $0.082^{* * *}$ & 0.313 & 0.248 & $0.065^{* * *}$ \\
\hline & & low & 0.205 & 0.251 & $-0.052^{* *}$ & 0.317 & 0.439 & $-0.122^{* * *}$ \\
\hline & & intermediate & 0.462 & 0.504 & $-0.042^{* *}$ & 0.425 & 0.396 & $0.029^{* * *}$ \\
\hline & & high & 0.320 & 0.209 & $0.110^{* * *}$ & 0.253 & 0.158 & $-0.095^{* * *}$ \\
\hline & & missing & 0.014 & 0.030 & $-0.017^{* * *}$ & 0.005 & 0.007 & $-0.002^{* *}$ \\
\hline & & household size & 2.780 & 2.751 & 0.029 & 2.688 & 2.785 & $-0.097^{* * *}$ \\
\hline & & mother German & 0.941 & 0.890 & $0.051^{* * *}$ & 0.886 & 0.833 & $0.053^{* * *}$ \\
\hline & & father German & 0.927 & 0.880 & $0.046^{* * *}$ & 0.891 & 0.836 & $0.055^{* * *}$ \\
\hline \multirow{6}{*}{ 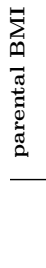 } & \multirow[t]{6}{*}{ father } & BMI & 25.95 & 27.90 & $-1.948^{* * *}$ & 26.06 & 27.43 & $-1.364^{* * *}$ \\
\hline & & missing & 0.084 & 0.116 & $-0.032^{* *}$ & 0.016 & 0.012 & $0.004^{* * *}$ \\
\hline & & BMI & 24.99 & 26.97 & $-2.983^{* * *}$ & 23.77 & 25.70 & $-1.933^{* * *}$ \\
\hline & & missing & 0.007 & 0.010 & -0.003 & 0.035 & 0.040 & $-0.004^{* *}$ \\
\hline & & $\%$ & 78.50 & 21.50 & & 76.76 & 23.24 & \\
\hline & & $\mathrm{N}$ & 1,921 & 526 & & 34,703 & 10,507 & \\
\hline
\end{tabular}

Note: ${ }^{a}$ approximated by the mother's current smoking status in Microcensus; ${ }^{*} \mathrm{p}<0.10,{ }^{* *} \mathrm{p}<0.05,{ }^{* * *} \mathrm{p}<0.01 ;$ Source: KiGGS 2003-2006; German Microcensus 1999, 2003, 2005, 2009 
Table A.2: Quantile Regression estimates of maternal employment on child BMI

\begin{tabular}{|c|c|c|c|c|c|c|c|c|c|}
\hline & OLS & $\mathrm{Q}(0.10)$ & $\mathrm{Q}(0.25)$ & $\mathrm{Q}(0.50)$ & $\mathrm{Q}(0.75)$ & $\mathrm{Q}(0.85)$ & $\mathrm{Q}(0.90)$ & $\mathrm{Q}(0.95)$ & $\mathrm{Q}(0.97)$ \\
\hline \multicolumn{10}{|l|}{ A: KiGGS } \\
\hline \multirow{2}{*}{$\begin{array}{l}\text { not employed } \\
\text { part-time }\end{array}$} & reference & reference & reference & reference & reference & reference & reference & reference & reference \\
\hline & $\begin{array}{l}0.0100 \\
(0.1426)\end{array}$ & $\begin{array}{l}-0.1788 \\
(0.1135)\end{array}$ & $\begin{array}{l}-0.1368 \\
(0.0949)\end{array}$ & $\begin{array}{l}-0.0317 \\
(0.1198)\end{array}$ & $\begin{array}{l}-0.0552 \\
(0.2226)\end{array}$ & $\begin{array}{l}-0.0158 \\
(0.3638)\end{array}$ & $\begin{array}{l}-0.1930 \\
(0.3757)\end{array}$ & $\begin{array}{l}-0.5855 \\
(0.3424)\end{array}$ & $\begin{array}{l}-0.4721 \\
(0.5556)\end{array}$ \\
\hline full-time & $\begin{array}{l}0.5345^{* *} \\
(0.1893)\end{array}$ & $\begin{array}{l}0.2240 \\
(0.1524)\end{array}$ & $\begin{array}{l}0.3070 \\
(0.1273)\end{array}$ & $\begin{array}{l}0.6114^{* * *} \\
(0.1605)\end{array}$ & $\begin{array}{l}0.4779 \\
(0.2938)\end{array}$ & $\begin{array}{l}0.7730 \\
(0.4669)\end{array}$ & $\begin{array}{l}0.7370 \\
(0.4708)\end{array}$ & $\begin{array}{l}1.1493^{*} \\
(0.4165)\end{array}$ & $\begin{array}{l}0.7651 \\
(0.6375)\end{array}$ \\
\hline $\mathrm{N}$ & 2,447 & 2,447 & 2,447 & 2,447 & 2,447 & 2,447 & 2,447 & 2,447 & 2,447 \\
\hline \multicolumn{10}{|c|}{ B: Microcensus } \\
\hline \multirow{2}{*}{$\begin{array}{l}\text { not employed } \\
\text { part-time }\end{array}$} & reference & reference & reference & reference & reference & reference & reference & reference & reference \\
\hline & $\begin{array}{l}-0.0276 \\
(0.0356)\end{array}$ & $\begin{array}{l}-0.0117 \\
(0.0394)\end{array}$ & $\begin{array}{l}0.0353 \\
(0.0359)\end{array}$ & $\begin{array}{l}0.0187 \\
(0.0390)\end{array}$ & $\begin{array}{l}-0.0486 \\
(0.0489)\end{array}$ & $\begin{array}{l}-0.0748 \\
(0.0610)\end{array}$ & $\begin{array}{l}-0.0078 \\
(0.0754)\end{array}$ & $\begin{array}{l}-0.0477 \\
(0.1123)\end{array}$ & $\begin{array}{l}-0.1681 \\
(0.1413)\end{array}$ \\
\hline full-time & $\begin{array}{l}0.3598^{* * * *} \\
(0.0509)\end{array}$ & $\begin{array}{l}0.1694 * * \\
(0.0535)\end{array}$ & $\begin{array}{l}0.2984 * * * \\
(0.0487)\end{array}$ & $\begin{array}{l}0.3740^{* * * *} \\
(0.0529)\end{array}$ & $\begin{array}{l}0.4148 * * * \\
(0.0663)\end{array}$ & $\begin{array}{l}0.4388^{* * * *} \\
(0.0827)\end{array}$ & $\begin{array}{l}0.4074^{* * *} \\
(0.1022)\end{array}$ & $\begin{array}{l}0.4050^{* *} \\
(0.1522)\end{array}$ & $\begin{array}{l}0.3587 \\
(0.1916)\end{array}$ \\
\hline $\mathrm{N}$ & 45,210 & 45,210 & 45,210 & 45,210 & 45,210 & 45,210 & 45,210 & 45,210 & 45,210 \\
\hline
\end{tabular}

Note: all models include a full range of control variables comparable to model $(5)$, Table $1 ;{ }^{*} \mathrm{p}<0.10,{ }^{* *} \mathrm{p}<0.05,{ }^{* * *} \mathrm{p}<0.01$; Source: KiGGS 2003-2006; German Microcensus 1999, 2003, 2005, 2009

Table A.3: Results of alternative IV estimation strategies on the effect of maternal full-time employment on child (over)weight

\begin{tabular}{|c|c|c|c|c|c|c|c|c|}
\hline Dependent & Mean & $\begin{array}{l}(1) \\
\text { OLS }\end{array}$ & $\begin{array}{l}(2) \\
\text { twosls }\end{array}$ & $\begin{array}{l}(3) \\
\text { gmm }\end{array}$ & $\begin{array}{l}(4) \\
\text { treatreg }(2 \mathrm{st})\end{array}$ & $\begin{array}{l}(5) \\
\text { treatreg(ML) }\end{array}$ & $\begin{array}{l}(6) \\
2 \mathrm{SRI}\end{array}$ & $\mathrm{N}$ \\
\hline \multicolumn{9}{|l|}{ A: KiGGS } \\
\hline BMI & $\begin{array}{l}18.4876 \\
(0.0680)\end{array}$ & $\begin{array}{l}0.5324^{* * *} \\
(0.1672)\end{array}$ & $\begin{array}{l}1.8607^{*} \\
(1.1056)\end{array}$ & $\begin{array}{l}1.9092^{*} \\
(1.1061)\end{array}$ & $\begin{array}{l}1.7663 \\
(1.1544)\end{array}$ & $\begin{array}{l}4.6750^{* * *} \\
(0.3180)\end{array}$ & $\begin{array}{l}1.3135^{*} \\
(0.8461)\end{array}$ & 2,447 \\
\hline overweight & $\begin{array}{l}0.2144 \\
(0.0082)\end{array}$ & $\begin{array}{l}0.0466^{* *} \\
(0.0225)\end{array}$ & $\begin{array}{l}0.2766^{* *} \\
(0.1333)\end{array}$ & $\begin{array}{l}0.2811^{* *} \\
(0.1333)\end{array}$ & $\begin{array}{l}0.2530^{*} \\
(0.1504)\end{array}$ & $\begin{array}{l}0.6652^{* * *} \\
(0.0310)\end{array}$ & $\begin{array}{l}0.1115 \\
(0.1128)\end{array}$ & 2,447 \\
\hline \multicolumn{9}{|c|}{ B: Microcensus } \\
\hline BMI & $\begin{array}{l}18.3235 \\
(0.0162)\end{array}$ & $\begin{array}{l}0.3765^{* * *} \\
(0.0454)\end{array}$ & $\begin{array}{l}2.8150^{* * *} \\
(0.3234)\end{array}$ & $\begin{array}{l}2.8114^{* * *} \\
(0.3234)\end{array}$ & $\begin{array}{l}2.8114^{\text {*** }} \\
(0.3315)\end{array}$ & $\begin{array}{l}4.3432^{\text {*** }} \\
(0.0857)\end{array}$ & $\begin{array}{l}1.6931^{* * *} \\
(0.2572)\end{array}$ & 45,210 \\
\hline overweight & $\begin{array}{l}0.2324 \\
(0.0020)\end{array}$ & $\begin{array}{l}0.0353^{* * *} \\
(0.0056)\end{array}$ & $\begin{array}{l}0.2815^{* * *} \\
(0.0403)\end{array}$ & $\begin{array}{l}0.2815^{* * *} \\
(0.0403)\end{array}$ & $\begin{array}{l}0.2790^{* * *} \\
(0.0416)\end{array}$ & $\begin{array}{l}0.7115^{* * *} \\
(0.0073)\end{array}$ & $\begin{array}{l}0.1746^{* * *} \\
(0.0325)\end{array}$ & 45,210 \\
\hline
\end{tabular}

Note: all models include a full range of control variables comparable to model (5), Table $1 ;{ }^{*} \mathrm{p}<0.10,{ }^{* *} \mathrm{p}<0.05,{ }^{* * *} \mathrm{p}<0.01$; Source: KiGGS 2003-2006; German Microcensus 1999, 2003, 2005, 2009 
Figure A.1: Maternal employment by the number of younger siblings (Microcensus)

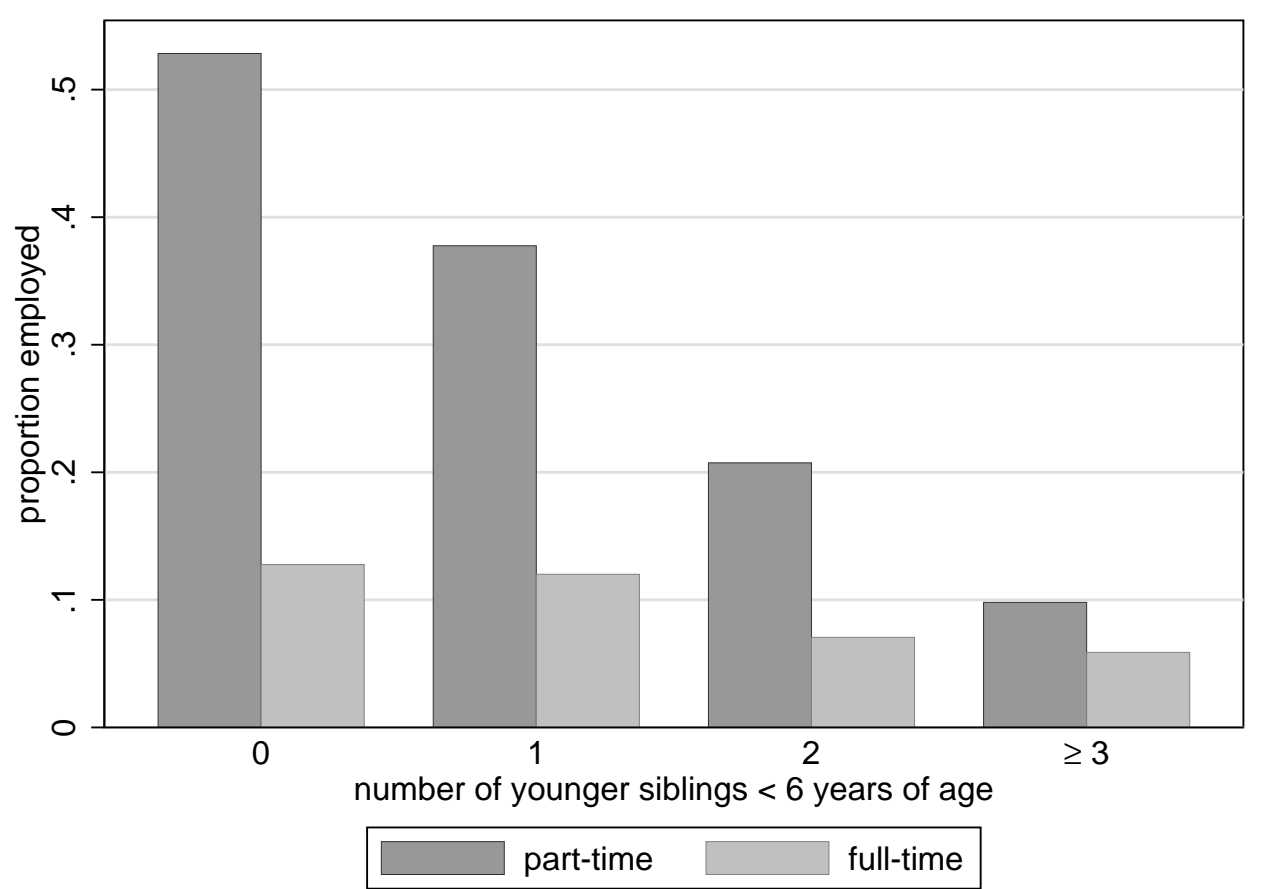

Source: German Microcensus 1999, 2003, 2005, 2009 